\title{
Obesity Surgery
}

\section{Effect of Bariatric Surgery on Cardiovascular Events and Metabolic Outcomes In Obese Patients with Insulin-treated Type 2 Diabetes: A Retrospective Cohort Study \\ --Manuscript Draft--}

\begin{tabular}{|c|c|}
\hline Manuscript Number: & \\
\hline Full Title: & $\begin{array}{l}\text { Effect of Bariatric Surgery on Cardiovascular Events and Metabolic Outcomes In } \\
\text { Obese Patients with Insulin-treated Type } 2 \text { Diabetes: A Retrospective Cohort Study }\end{array}$ \\
\hline Article Type: & Original Contribution \\
\hline Keywords: & insulin; type 2 diabetes; cardiovascular, peripheral vascular disease \\
\hline Corresponding Author: & $\begin{array}{l}\text { iskandar idris } \\
\text { Universityo f Nottingham } \\
\text { UNITED KINGDOM }\end{array}$ \\
\hline $\begin{array}{l}\text { Corresponding Author Secondary } \\
\text { Information: }\end{array}$ & \\
\hline Corresponding Author's Institution: & Universityo f Nottingham \\
\hline $\begin{array}{l}\text { Corresponding Author's Secondary } \\
\text { Institution: }\end{array}$ & \\
\hline First Author: & iskandar idris \\
\hline First Author Secondary Information: & \\
\hline Order of Authors: & iskandar idris \\
\hline & Mohammed Alkharaiji, BSs MSc \\
\hline & Uchenna Anyanwagu, MD PhD \\
\hline & Richard Donnelly, MD PhD FRCP \\
\hline Order of Authors Secondary Inform & \\
\hline Funding Information: & \\
\hline Abstract: & 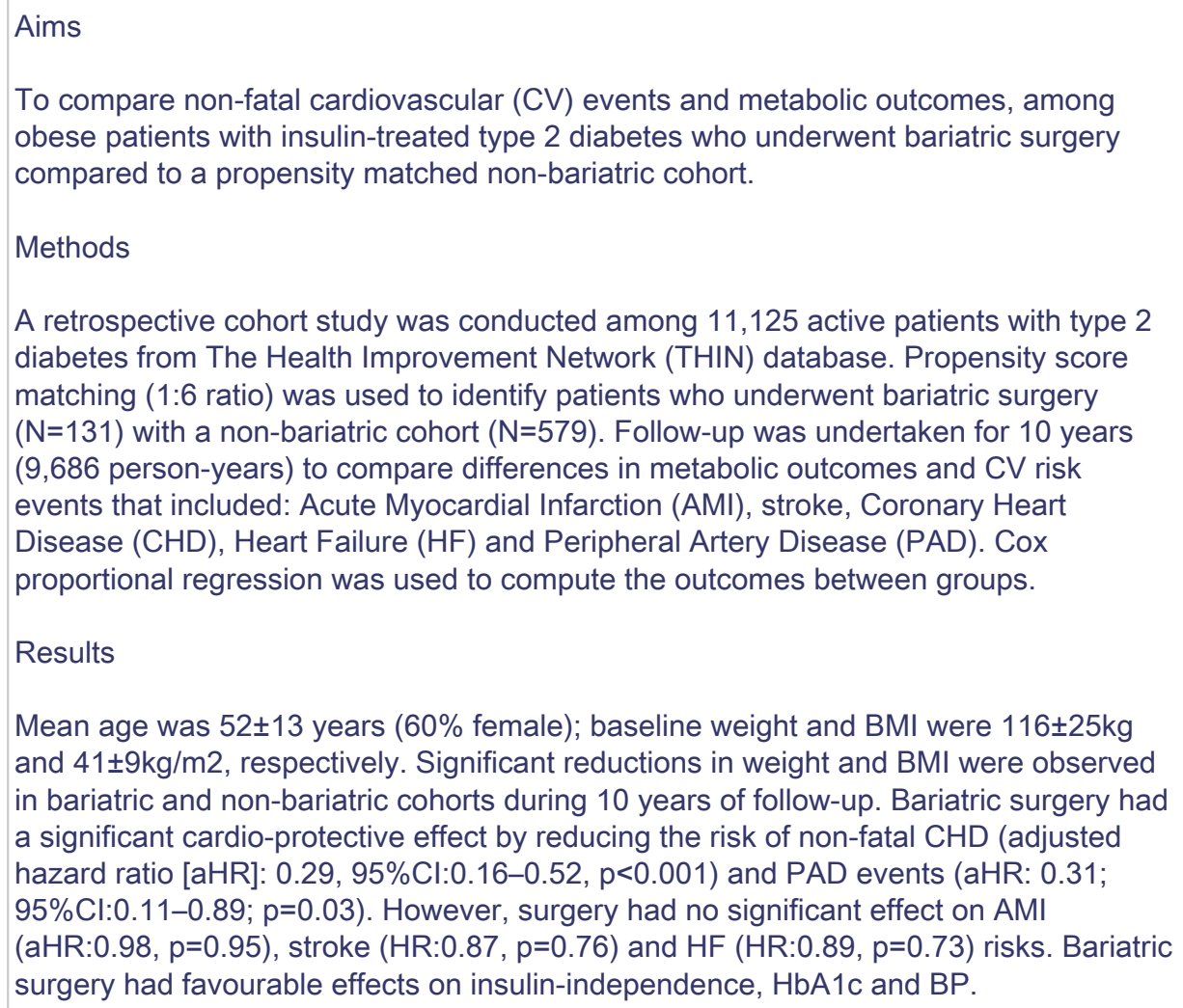 \\
\hline
\end{tabular}




\section{Conclusion}

Among obese insulin-treated patients with type 2 diabetes, bariatric surgery is associated with significant reductions in non-fatal CHD and PAD events, lower body weight, BP, and a greater likelihood of insulin independence during 10 years of followup. 


\section{Title}

Effect of Bariatric Surgery on Cardiovascular Events and Metabolic Outcomes In Obese Patients with Insulin-treated Type 2 Diabetes: A Retrospective Cohort Study

Mohammed Alkharaiji ${ }^{1,2}$, Uchenna Anyanwagu ${ }^{1}$, Richard Donnelly ${ }^{1}$, Iskandar IDRIS ${ }^{1 *}$

${ }^{1}$ Division of Medical Sciences \& Graduate Entry Medicine, School of Medicine, University of Nottingham, Derby, UK, ${ }^{2}$ Faculty of Public Health, College of Health, The Saudi Electronic University, Riyadh, Saudi Arabia, *Correspondent

Correspondence: A/Prof Iskandar Idris, Division of Medical Sciences \& Graduate Entry Medicine, University of Nottingham, Royal Derby Hospital, Derby, UK

Email: Iskandar.idris@nottingham.ac.uk

\section{Conflicts of interest: $\underline{\text { None }}$}




\section{Abstract}

Aims: To compare non-fatal cardiovascular (CV) events and metabolic outcomes, among obese patients with insulin-treated type 2 diabetes who underwent bariatric surgery compared to a propensity matched non-bariatric cohort.

Methods: A retrospective cohort study was conducted among 11,125 active patients with type 2 diabetes from The Health Improvement Network (THIN) database. Propensity score matching (1:6 ratio) was used to identify patients who underwent bariatric surgery $(\mathrm{N}=131)$ with a non-bariatric cohort $(\mathrm{N}=579)$. Follow-up was undertaken for 10 years $(9,686$ personyears) to compare differences in metabolic outcomes and CV risk events that included: Acute Myocardial Infarction (AMI), stroke, Coronary Heart Disease (CHD), Heart Failure (HF) and Peripheral Artery Disease (PAD). Cox proportional regression was used to compute the outcomes between groups.

Results: Mean age was $52 \pm 13$ years (60\% female); baseline weight and BMI were $116 \pm 25 \mathrm{~kg}$ and $41 \pm 9 \mathrm{~kg} / \mathrm{m}^{2}$, respectively. Significant reductions in weight and BMI were observed in bariatric and non-bariatric cohorts during 10 years of follow-up. Bariatric surgery had a significant cardio-protective effect by reducing the risk of non-fatal CHD (adjusted hazard ratio [aHR]: 0.29, 95\% Cl:0.16-0.52, p<0.001) and PAD events (aHR: 0.31; 95\%Cl:0.11-0.89; $p=0.03)$. However, surgery had no significant effect on AMI (aHR:0.98, $p=0.95)$, stroke (HR:0.87, $p=0.76)$ and HF (HR:0.89, $p=0.73)$ risks. Bariatric surgery had favourable effects on insulin-independence, $\mathrm{HbA} 1 \mathrm{c}$ and $\mathrm{BP}$.

Conclusion: Among obese insulin-treated patients with type 2 diabetes, bariatric surgery is associated with significant reductions in non-fatal CHD and PAD events, lower body weight, $\mathrm{BP}$, and a greater likelihood of insulin independence during 10 years of follow-up. 
What is already known about this subject?

- Obesity and type 2 diabetes are associated with high risk of cardiovascular events

- Obesity is causally associated with peripheral artery disease

- Insulin -treated type 2 diabetes is associated with additional excess risk of cardiovascular events

- Bariatric surgery in people with or without diabetes reduces cardiovascular events

What does this study add?

- This study focuses on insulin treated type 2 diabetes - recently recognised to be associated with higher risks of cardiovascular events

- Among insulin treated type 2 diabetes, bariatric surgery is associated with significant reduction in non-fatal coronary heart disease and peripheral artery disease

- Among insulin treated type 2 diabetes, bariatric surgery is associated with significant reduction and maintenance of weight loss, significant reduction in $\mathrm{HbA1c}$, with relapse of HbA1c levels after 6 years of follow up and significant increase of insulin independence

How might this impact on clinical practice?

- Bariatric surgery should be considered as a genuine therapeutic option for the management of obese insulin treated type 2 diabetes to reduce coronary heart disease, peripheral artery disease events, reduce $\mathrm{HbA1c}$ levels and potentially reduce long-term risk of microvascular complications of diabetes as well as inducing insulin indepence. 


\section{Background}

Obesity and Type 2 diabetes (T2D) are major global health problems that are intrinsically linked with adverse cardiovascular (CV) outcomes ${ }^{1,2}$. Obesity-associated coronary artery disease and myocardial dysfunction have been shown to be a direct consequence of excess dysfunctional adipose tissue, driven by increased pro-inflammatory state, insulin resistance, endothelial dysfunction and the development of myocardial hypertrophy ${ }^{3}$. Consequently, weight loss by any means has been shown to improve CV outcomes ${ }^{4}$. Although diet and exercise play a crucial role in obesity management, lifestyle alone may not achieve durable weight loss in the majority of patients ${ }^{5}$. Bariatric surgery therefore has emerged as the most effective and durable strategy for long-term weight loss in morbidly obese individuals ${ }^{6}$. The two most commonly performed bariatric surgical procedures are the Roux-en-Y gastric bypass (RYGB) and sleeve gastrectomy (SG). Indeed, previous studies have shown beneficial effects of these bariatric surgical procedures on CV outcomes ${ }^{7-9}$.

Many patients with T2D will require insulin treatment to manage hyperglycaemia, to reduce the risk of long-term vascular complications ${ }^{10}$. However, insulin therapy is known to induce $\sim 4-9 \mathrm{~kg}$ weight gain in the first year of treatment, while escalation of insulin treatment doses are associated with greater weight gain ${ }^{11}$ and excess $\mathrm{CV}$ risk ${ }^{12}$. Furthermore, evidence from randomized controlled trial and observational studies have implicated insulin therapy in patients with T2D with increased CV risk and mortality ${ }^{13-16}$, possibly due to weight gain, recurrent hypoglycaemia and iatrogenic hyperinsulinemia ${ }^{17,18}$. Thus, a cohort of insulintreated patients with T2D, represent a complex heterogenous, challenging group of patients, many of whom have significant comorbidities and high CV disease risk. No studies have assessed the effect bariatric surgery on cardiovascular outcomes among insulin-treated patients with T2D in routine clinical care. 


\section{Methods}

\section{Study design, data sources and study population}

This was a retrospective cohort study that used The Health Improvement Network (THIN), an anonymised health care records derived from over 600 UK general practices, containing details on demographics, lifestyle characteristics, major medical and surgical conditions, drug utilisation, and health outcomes of over 17 million patients, 3.1 million of which are active patients ${ }^{19}$. Our dataset contains all adult patients (age $>18$ years) with T2D and have been prescribed with any form of insulin therapy up to September $2017(\mathrm{~N}=11,125)$. Patients' index date was either the day of bariatric surgery (RYGB or SG) or, in case they have not received bariatric surgery, first intensification of insulin therapy. We excluded patients with type 1 diabetes or non- insulin-treated T2D. Ethics approval was provided by the NHS South East Multi-centre Research Ethics Committee (MREC).

\section{Exposure and outcomes}

Exposure of interest is bariatric surgery (RYGB or SG). Patients were censored throughout 10 years of follow-up - following the development of primary outcome, transferred out, loss to follow-up or at the end of the study. Primary outcome was patients' survivability against nonfatal CV events with further stratification to include CV events into divisions of time to the risk of Acute Myocardial Infarction (AMI), stroke, Coronary Heart Disease (CHD), Heart Failure (HF) and Peripheral Artery Disease (PAD). Secondary outcomes included health covariates such as body weight, calculated $\mathrm{BMI}, \mathrm{HbA1c}$, total cholesterol, systolic/diastolic blood pressure and insulin independence.

\section{Covariates and follow-up strategy}

We followed-up the treatment group whom underwent bariatric surgery and compared with their propensity-matched (PS) matched non-bariatric surgery from their first insulin prescription date up to the endpoint of 10-year of follow-up. Patients with CV events prior to the designated baseline point were excluded from the primary survival estimation on each stratified CV element. Baseline clinical parameters (average values from multiple entries) were measured at the same time window according to patient's treatment category, i.e. 90 
days up to one day before the surgery date or first intensification of insulin therapy. Covariates were, then, recalculated at 6-month, and at each year point up to 10 years of follow-up; with 90 days window on every concurring point of time.

\section{Statistical analysis}

Primary analysis was time to the risk of stratified non-fatal CV events that included AMI, stroke, CHD, HF and PAD in a PS-matched groups. The PS model was estimated by using logistic regression model to adjust for baseline characteristics, thus, minimising allocation bias between groups. The balance assessment was made between bariatric (treated) and nonbariatric (untreated) groups by measuring standardised differences before and after the matching procedure. The mean form continuous covariates and proportion of categorical variables between groups were examined and summarised. Each treatment subject was matched to six reference subjects at the nearest distance measured by the estimated PS, based on the estimated treatment probabilities ${ }^{20}$. We employed caliper width $=0.05$ of the standard deviation of the logit of the PS to minimise distance within matched sets which may improve match quality but would limit excessive number of matched subjects ${ }^{21}$. A caliper width of $<0.2$ has been shown to result in optimal estimation compared to higher choices of caliper use ${ }^{22}$. PS was included in all Cox proportional hazards regression modelling as it was considered a prognostic covariate. Stratified log-rank test, with Kaplan-Meier survival curves respectively was used to compare the equality between the PS-matched groups. The absolute reduction in the probability of an event occurring within 10-year follow-up was calculated. Marginal hazard ratios were estimated to quantify the adjusted hazard of an event occurred in the bariatric group compared to the matched non-bariatric group. Proportional hazards assumptions were confirmed through Schoenfeld residuals test. Point estimates with 95\% Confidence Intervals ( $\mathrm{Cls}$ ) at the conventional statistical significance level of 0.05 were used in the regression models. The proportional hazards assumption was examined by comparing the cumulative hazard plots grouped on exposure; no violations were observed.

Missing data among covariates were managed through multiple imputations using the predictive means matching for continuous covariates with accounting to exposure (i.e. bariatric), age, gender, diabetes duration, Townsend deprivation status, marital status, 
smoking and alcohol use $\mathrm{e}^{23}$. To test the adequacy of our multiple imputation approach in addressing the impact of some missing data, we conducted a sensitivity analysis wherein the primary endpoints in the imputed dataset and were compared with the dataset with missing values and found to be similar, thereby affirming the robustness of the imputation method employed before PS matching procedure was performed ${ }^{24}$.

We used Student's t-test to estimate the mean changes in continuous variables (e.g. body weight \& HbA1c) in both PS matched groups throughout 10-year of follow-up compared to their baseline measurements; and Pearson $X^{2}$ to test on the likelihood of being off insulin at 5 and 10 years from the baseline. Statistical significance was put at a p level of 0.05 . To avoid the probability of type II error, the study was powered to 0.8 and the matched sample size of 710 was found to detect a true difference of less than 0.1 between the two groups at $5 \%$ significance level. The study fulfilled the STROBE criteria for reporting observational studies. Throughout, we used SAS Software version 9.4 in the initial dataset management (SAS Institute, Cary, NC); Stata Statistical Software version 15.1 in all carried analysis (StataCorp., College Station, TX); and GraphPad/Prism version 8.0 for visualisation (La Jolla, CA). 


\section{Results}

\section{Patients' characteristics and total follow-up}

From 11,125 patients with insulin-treated T2D, we identified 155 patients who have had bariatric surgical operation. The PS matching procedure allowed 131 bariatric patients to be matched with up to six control subjects. This yielded a total number of 710 PS-matched participants. The median treatment duration was 10.07 years (interquartile range (IQR): 6.1114.31 years). The median follow-up was 8.42 years (IQR: $2.92-14.58$ years) representing a total follow-up period of 9,686 person-years.

In the matched cohort, the overall mean of age was 51.7 (SD 12.5) years; $59.6 \%$ were females. The mean body weight, BMI and HbA1c level were 115.7 (SD 25.4) kg, 40.7 (SD 9.2) kg/m² and 71.2 (SD 18.1) $\mathrm{mmol} / \mathrm{mol}$, respectively. The baseline characteristics in both bariatric and nonbariatric groups were compared between the full and matched cohort with their standardised differences shown in Table 1.

\section{Cardiovascular event rates}

The probability of survival for non-fatal CHD was significantly different between matched bariatric and non-bariatric groups at 1 -year (98.0\% vs $89.6 \%)$, 5-year (92.2\% vs $67.6 \%$ ) and 10year (88.2\% vs 51.6\%) of follow-up (log-rank test $p<0.001$ ) (Fig. 1c). A total of 277 (18 vs 259) events were reported with a crude event rate of 52.4 (21.4 vs 58.2) per 1000 person-years (95\% Cl 46.6-58.9). The probability of survival for non-fatal PAD was also significantly different at 5-year (90.5\% vs $78.8 \%$ ) and 10 -year (84.0\% vs 53.1\%) of follow-up (log-rank test $p=0.007$ ) (Fig. 1e). A total of 59 (6 vs 53) events were observed with a crude event rate of 62.1 (25.9 vs 73.8 ) per 1000 person-year (95\% Cl 48.1-80.2). The probabilities of survival for non-fatal AMI, stroke and HF were with little or no statistical significance between the matched groups throughout 10 years of follow-up (log-rank test $p>0.5)$ (Fig. 1a, 1b \& 1d). Table 2 shows a summary of the events for each of the stratified CV components with absolute event rates.

\section{Risk of cardiovascular disease}


Bariatric surgery was protective against all analysed CV elements in the matched cohort. The risk of non-fatal CHD and PAD in the bariatric group were significantly lower (by $71 \%$ \& $69 \%$, respectively) compared to the matched non-bariatric group (CHD aHR: $0.29,95 \% \mathrm{Cl} 0.16-0.52$, $\mathrm{p}<0.001$; PAD aHR: 0.31, 95\% Cl 0.11-0.89, $\mathrm{p}=0.03$ ) adjusted for age, $\mathrm{HbA1c}$ level, diabetes duration, oral antidiabetic drug use, diuretics use, antihypertensive drug use, Townsend deprivation status, alcohol use and smoking status. Despite protective tendency against nonfatal AMI, stroke and HF, none of which was found with statistical significance (AMI aHR: 0.98, 95\% Cl 0.54-1.77, $p=0.94$; stroke aHR: $0.87,95 \% \mathrm{Cl} 0.36-2.10, \mathrm{p}=0.75 ; \mathrm{HF}$ aHR: $0.89,95 \% \mathrm{Cl}$ 0.47-1.70, $p=0.73$ ) (Table 2).

\section{Changes in metabolic outcomes}

Significant reductions in the matched cohort (i.e. $p<0.001$ ) favouring the bariatric group vs non-bariatric was observed in terms of body weight and BMI throughout all 10 years of followup compared to baseline. Body weight and BMI for bariatric vs non-bariatric were: at 1-year point ( $97.5 \pm 24.2$ vs $109.8 \pm 18.6 \mathrm{~kg} ; 34.2 \pm 9.0$ vs $38.8 \pm 7.4 \mathrm{~kg} / \mathrm{m}^{2}$, respectively), at 5 -year point (98.9 \pm 23.3 vs $107.1 \pm 18.2 \mathrm{~kg} ; 34.8 \pm 9.2$ vs $37.8 \pm 7.3 \mathrm{~kg} / \mathrm{m}^{2}$, respectively), and at 10 -year point (94.1 \pm 20.1 vs $107.6 \pm 17.3 \mathrm{~kg} ; 32.9 \pm 7.7$ vs $38.0 \pm 7.1 \mathrm{~kg} / \mathrm{m}^{2}$, respectively) of follow-up (Fig. 2a \& 2b). The reduction in $\mathrm{HbA1c}$ was statistically significant up to six years of follow-up. At the first year the level of $\mathrm{HbA1c}$ in the bariatric vs non-bariatric $(60.3 \pm 18.2$ vs $72.0 \pm 17.9$ $\mathrm{mmol} / \mathrm{mol})$, at 3-year point $(66.1 \pm 16.8$ vs $71.3 \pm 17.8 \mathrm{mmol} / \mathrm{mol})$ and at 6 -year point $(68.1 \pm 16.9$ vs $72.8 \pm 18.8 \mathrm{mmol} / \mathrm{mol})$. No statistical difference was observed beyond the seventh year in the HbA1c level between the matched groups (Fig. 2c). Total cholesterol was significantly reduced during the first six months of follow-up $(4.12 \pm 0.99 \mathrm{vs} 4.50 \pm 1.14 \mathrm{mmol} / \mathrm{L}$, $p=0.008$ ) (Fig. 2d). Blood pressure was also significantly reduced early following the bariatric surgery. The systolic blood pressure at 6 -month point ( $130 \pm 18$ vs $137 \pm 16 \mathrm{mmHg}, \mathrm{p}<0.001)$ and at 1-year point (133 \pm 17 vs $137 \pm 15 \mathrm{mmHg}, \mathrm{p}=0.07$ ) (Fig. 2e). The diastolic blood pressure was significantly reduced in the bariatric vs non-bariatric $(p<0.05)$ up to two years of followup (6-month: $76 \pm 10$ vs 79 \pm 9 ; 1-year: $77 \pm 9$ vs $79 \pm 9$; 2 -year: $76 \pm 10$ vs $79 \pm 10 \mathrm{mmHg}$ ) (Fig. 2f).

Figure 2 represents reduction in the matched cohort of the analysed outcome variables during 10 years of follow-up in comparison to their baseline measurements with $95 \%$ confidence intervals. 
The analysis of the matched groups also revealed that, at one year of follow-up, $6.4 \%$ of whom underwent bariatric surgery were insulin independent compared to $7.9 \%$ non-bariatric with little or no statistical significance of a difference $\left(X^{2}=0.35, p=0.55\right)$. At three years, $31.2 \%$ of bariatric patients were independent from insulin use compared to $17.6 \%$ non-bariatric $\left(X^{2}=10.59, p=0.001\right)$. At six years, $41.5 \%$ of bariatric patients were independent from using insulin compared to $22.2 \%$ non-bariatric $\left(X^{2}=11.47, p=0.001\right)$. At 10 years, $77.5 \%$ of bariatric patients were independent from using insulin compared to $33.7 \%$ non-bariatric $\left(X^{2}=28.71, p\right.$ $<0.0001)$.

\section{Discussion}

This study showed that, among morbidly obese patients with insulin-treated T2D in routine clinical practice, bariatric surgery was associated with a significant $71 \%$ risk reduction in nonfatal CHD and $69 \%$ reduction in PAD events, as well as significant reductions in weight, $\mathrm{HbA1C}$, insulin independence and blood pressure. However, no significant reductions was observed with $\mathrm{AMI}$, stroke and heart failure.

Our findings were similar in pattern with previous observational studies on bariatric surgery with regards to cardiovascular and metabolic benefits ${ }^{7-9}$. Our study however focuses on patients with Insulin-treated T2D - known to be associated with higher risks of cardiovascular events $^{13-16}$. Indeed, a previous study have shown that while bariatric surgery reduces cardiovascular events and mortality, the mortality risk in people with diabetes after bariatric surgery remains $35 \%$ higher than that of the general population. ${ }^{25}$ Our study therefore extends evidence of cardiovascular benefit of bariatric surgery in this patient cohort whose residual $\mathrm{CV}$ risk are likely to be higher. Interestingly, a previous study in patients with diabetes reported a reduction in myocardial infarction but no effect was observed on stroke incidence ${ }^{8}$. However, a factor-treatment interaction analysis showed that the effect of bariatric surgery on AMI was greater in participants with higher total cholesterol and triglyceride levels, implying that those with dyslipidemia were the ones who are likely to gain the most benefit. Since our PS-matched cohort have optimal mean LDL-cholesterol and triglyceride levels ( 2.4 and $2.3 \mathrm{mmol} / \mathrm{L})$, respectively due to high use of statin therapy, this may explain the lack of significant reduction 
of AMI in our cohort while highlighting the importance of statin therapy in this patient cohort. Our observation of significant reduction in PAD events within this patient cohort is novel and have major clinical significant. A recent study have concluded that obesity is causally associated with PAD after controlling for potential confounders like hypertension, dyslipidemia and hyperglycemia ${ }^{26}$.

Insulin therapy is known to induce weight gain ${ }^{11}$. Our data showed a major reduction in weight following bariatric surgery, which persisted at 10 years of follow up. While greater significant reduction in weight following bariatric surgery compared with control is anticipated, it is interesting to note that weight loss was also observed in our PS-matched control cohort. This is likely due to concurrent use of GLP-1 analogue in our patient cohort. Evidence of weight loss with GLP-1 as adjunct to insulin treatment has been shown in randomized controlled trials. ${ }^{27,28}$ In addition, we have also reported significant weight loss after 12 months of adding a GLP-1 to insulin therapy in routine clinical practice ${ }^{29}$. Of note, weight loss was not observed in our non- PS-matched control cohort, indicating robust PS matching protocol used in this study analysis (Supplement). The addition of GLP-1 therapy, in combination with use of other novel weight loss antidiabetic regimens like sodium glucose co-tranporter-2 (SGLT-2) inhibitor, as well as significant calorie restriction may also explain the smaller but appreciable percentage of patients who were insulin independence in the PSmatched control cohort, compared with those who underwent bariatric surgery. Interestingly, in contrast to the observed weight loss which persisted over 10 years of followup, the reduction in $\mathrm{HbA1c}$ was statistically significance only up to six years of follow-up postsurgery, with a rise in $\mathrm{HbA1c}$ during further follow-up. Previous studies comparing bariatric surgery outcomes with medical/lifestyle intervention have mainly reported $\mathrm{HbA} 1 \mathrm{c}$ reduction up to five years post surgery ${ }^{30-32}$, albeit in patients with T2D irrespective of treatment regimen. The discordance between long-term weight and $\mathrm{HbA1c}$ outcomes suggested that the observed relapse in $\mathrm{HbA} 1 \mathrm{c}$ level was independent of weight regain. Nonetheless, any beneficial effects of bariatric surgery on weight, $\mathrm{HbA} 1 \mathrm{c}$ reduction and insulin independence will have significant impact on the long-term risk of vascular complications of diabetes and will likely confer cost savings to the UK National Health Service in the long-term. 
The main strength of our study derives from the inclusion of a relatively large cohort of insulintreated T2D in a real-world population which can be generalized to the UK or similar population. This implies that our findings will be generalizable to various population with similar demographics. The cohort of patients studied here provides adequate statistical power and also contains information on other time-varying covariates to adjust for possible confounders. We adjusted for a large set of factors that could have differed at the baseline through a robust PS-matching protocol. This is crucial since the decision to have bariatric surgery in routine clinical practice is often based on multiple factors, not confided to UK NICE guidelines. Nevertheless, some residual confounding in our study could persists due to our inability to measure and adjust for the dosage of the insulin therapy as well as the reliability of diabetes duration due to the ongoing issue of identifying incident versus prevalent diabetes. Also, the classification of exposure into two broad types of bariatric surgery could have possibly masked the effects of individual types of bariatric surgery and could have driven our study away or closer to the null hypothesis. Nonetheless, previous high profile studies on cardiovascular benefits of bariatric surgery have not looked at individual types of surgery.

In summary, this study suggests that bariatric surgery in morbidly obese patients with insulintreated T2D is associated with a significant reduction in a non-fatal CHD and PAD events, as well as significant reduction in weight, $\mathrm{HbA} 1 \mathrm{c}$ and insulin independence compared with matched control. The mechanism for this cardio-protective effects remained speculative but further study is required to confirm this observation. 


\section{References}

1 Finucane MM, Stevens GA, Cowan MJ, et al. Global Burden of Metabolic Risk Factors of Chronic Diseases Collaborating Group (Body Mass Index) National, regional, and global trends in body-mass index since 1980: systematic analysis of health examination surveys and epidemiological studies with 960 country-years and 9.1 million participants. Lancet 2011;377:557-567

2 Adams KF, Schatzkin A, Harris TB, et al. Overweight, obesity, and mortality in a large prospective cohort of persons 50 to 71 years old. N Engl J Med 2006;355:763-778

3 Bays HE Adiposopathy is "sick fat" a cardiovascular disease? J Am Coll Cardiol 2011;57:2461-73

$4 \quad$ Vidal J. Updated review on the benefits of weight loss. Int J Obes Relat Metab Disord. 2002;26(Suppl 4):S25-S28

5 Dombrowski SU, Knittle K, Avenell A, Araujo-Soares V, Sniehotta FF. Long term maintenance of weight loss with non-surgical interventions in obese adults: systematic review and meta-analyses of randomised controlled trials. BMJ 2014; 348: g2646

6 Golzarand $\mathrm{M}$, Toolabi K, Farid R. The bariatric surgery and weight losing: a metaanalysis in the long- and very long-term effects of laparoscopic adjustable gastric banding, laparoscopic Roux-en-Y gastric bypass and laparoscopic sleeve gastrectomy on weight loss in adults. Surg Endosc. 2017;31:4331-4345.

7 Eliasson B , Liakopoulos V, Franzén S, Näslund I, Svensson AM, Ottosson J, Gudbjörnsdottir S. Cardiovascular disease and mortality in patients with type 2 diabetes after bariatric surgery in Sweden: a nationwide, matched, observational cohort study. Lancet Diabetes Endocrinol. 2015;3:847-54.

8 Romeo S, Maglio C, Burza MA, Pirazzi C, Sjöholm K, Jacobson P, Svensson PA, Peltonen M, Sjöström L, Carlsson LM. Cardiovascular events after bariatric surgery in obese subjects with type 2 diabetes. Diabetes Care. 2012; 35:2613-7.

9 Vest AR1, Heneghan HM, Agarwal S, Schauer PR, Young JB. Bariatric surgery and cardiovascular outcomes: a systematic review. Heart. 2012; 98:1763-77.

10 Holman RR, Paul SK, Bethel MA, Matthews DR, Neil HA. 10-year follow-up of intensive glucose control in type 2 diabetes. N Engl J Med 2008; 359: 1577-89. 
11 Russell-Jones D, Khan R. Insulin-associated weight gain in diabetes - causes, effects and coping strategies. Diabetes, Obesity and Metabolism 2007; 9(6): 799-812.

12 Herman ME, O'Keefe JH, Bell DSH, Schwartz SS. Insulin Therapy Increases Cardiovascular Risk in Type 2 Diabetes. Prog Cardiovasc Dis. 2017; 60:422-434.

13 The Action to Control Cardiovascular risk in diabetes study Group. Effects of Intensive Glucose lowering in type 2 Diabetes. New England J Med. 2008; 358:2545

14 Holman RR, Sourij H, Califf RM. Cardiovascular outcome trials of glucose-lowering drugs or strategies in type 2 diabetes. Lancet 2014; 383(9933): 2008-17.

15 Currie CJ, Poole CD, Evans M, Peters JR, Morgan CL. Mortality and other important diabetes-related outcomes with insulin vs other antihyperglycemic therapies in type 2 diabetes. J Clin Endocrinol Metab 2013; 98(2): 668-77.

16 Roumie CL, Greevy RA, Grijalva CG, et al. Association between intensification of metformin treatment with insulin vs sulfonylureas and cardiovascular events and allcause mortality among patients with diabetes. Jama 2014; 311(22): 2288-96.

17 Muniyappa R, lantorno M, Quon MJ. An integrated view of insulin resistance and endothelial dysfunction. Endocrinol Metab Clin North Am. 2008; 37:685-711

18 Van Avendonk MWJ, Rutten GEH. Insulin therapy in type 2 diabetes: what is the evidence? Diabetes, Obesity and Metabolism 2009; 11(5):415-432.

19 The Heath Improvement Network (THIN). 2018; Available from: https://www.iqvia.com/locations/uk-and-ireland/thin.

20. Garrido, M.M., et al., Methods for Constructing and Assessing Propensity Scores. Health Services Research, 2014. 49: p. 1701-1720.

21. Rassen, J.A., et al., One-to-many propensity score matching in cohort studies. Pharmacoepidemiology and Drug Safety, 2012. 21(S2): p. 69-80.

22. Austin, P.C., Statistical Criteria for Selecting the Optimal Number of Untreated Subjects Matched to Each Treated Subject When Using Many-to-One Matching on the Propensity Score. American Journal of Epidemiology, 2010. 172: p. 1092-1097.

23. Morris, T.P., I.R. White, and P. Royston, Tuning multiple imputation by predictive mean matching and local residual draws. BMC Medical Research Methodology, 2014. 14: p. 75. 
24. Eulenburg, C., et al., Propensity Scoring after Multiple Imputation in a Retrospective Study on Adjuvant Radiation Therapy in Lymph-Node Positive Vulvar Cancer. PLoS ONE, 2016. 11: p. e0165705.

25 Dhalwani NN, Zaccardi F, Waheed H, Mytton J, Papamargaritis D, Webb DR, Evison F, Lilford R, Davies MJ, Khunti K. Cardiovascular, cancer and mortality events after bariatric surgery in people with and without pre-existing diabetes: A nationwide study. J Diabetes. 2018. doi: 10.1111/1753-0407.12851. [Epub ahead of print]

26 Huang $Y, X u$ M, Xie L, Wang T, Huang X, Lv X, Chen Y, Ding L, Lin L, Wang W, Bi Y, Sun Y, Zhang Y, Ning G. Obesity and peripheral arterial disease: A Mendelian Randomization analysis. Atherosclerosis. 2016;247:218-24.

27 Ekelund M, Filipsson K, Tengmark BO, Sjöberg S, Pehrsson NG. Liraglutide in people treated for type 2 diabetes with multiple daily insulin injections: randomised clinical trial (MDI Liraglutide trial). BMJ. 2015;351:h5364.doi: 10.1136/bmj.h5364.

28 Mathieu C, Rodbard HW, Cariou B, et al; BEGIN: VICTOZA ADD-ON (NN1250-3948) study group. A comparison of adding liraglutide versus a single daily dose of insulin aspart to insulin degludec in subjects with type 2 diabetes (BEGIN: VICTOZA ADD-ON). Diabetes Obes Metab 2014; 16:636-44.

29 Anyanwagu U, Mamza J, Donnelly R, Idris I. Effect of adding GLP-1RA on mortality, cardiovascular events, and metabolic outcomes among insulin-treated patients with type 2 diabetes: A large retrospective UK cohort study. Am Heart J. 2018;196:18-27

30 Schauer PR, Bhatt DL, Kirwan JP, et al.; STAMPEDE Investigators. Bariatric surgery versus intensive medical therapy for diabetes-3-year outcomes. N Engl J Med 2014;370:2002-2013

31 Mingrone G, Panunzi S, De Gaetano A, et al. Bariatric-metabolic surgery versus conventional medical treatment in obese patients with type 2 diabetes: 5 year followup of an open-label, singlecentre, randomised controlled trial. Lancet 2015; 386:964973

32. Ikramuddin S, Korner J, LeeW-J, et al. Rouxen-Y gastric bypass vs intensive medical management for the control of type 2 diabetes, hypertension, and hyperlipidemia: the Diabetes Surgery Study randomized clinical trial. JAMA 2013;309:2240-2249 
Table 1. Baseline characteristics

\begin{tabular}{|c|c|c|c|c|c|c|}
\hline \multirow[b]{3}{*}{ Baseline variable } & \multicolumn{6}{|l|}{ Cohort } \\
\hline & \multicolumn{3}{|c|}{$\begin{array}{l}\text { Full population } \\
{[N=11,125]}\end{array}$} & \multicolumn{3}{|c|}{$\begin{array}{l}\text { Propensity matched } \\
{[N=710]}\end{array}$} \\
\hline & $\begin{array}{l}\text { Bariatric } \\
{[n=155]}\end{array}$ & $\begin{array}{l}\text { Non-bariatric } \\
{[n=10,970]}\end{array}$ & Std. diff* & $\begin{array}{l}\text { Bariatric } \\
{[n=131]}\end{array}$ & $\begin{array}{l}\text { Non-bariatric } \\
{[n=579]}\end{array}$ & Std. difft \\
\hline \multicolumn{7}{|l|}{ Demographics } \\
\hline Age (yrs), mean (SD) & $50.01(11.1)$ & $57.71(13.3)$ & -0.694 & $50.74(11.0)$ & $51.96(12.8)$ & -0.110 \\
\hline \multicolumn{7}{|l|}{ Gender, no (\%) } \\
\hline Female & $89(57.4)$ & $5068(46.2)$ & 0.224 & $73(55.4)$ & $351(60.6)$ & -0.107 \\
\hline \multicolumn{7}{|l|}{ Townsend deprivation, \% } \\
\hline Least deprived & 14.0 & 21.7 & -0.204 & 15.7 & 17.3 & -0.044 \\
\hline Less & 24.3 & 20.7 & 0.086 & 24.0 & 18.1 & 0.145 \\
\hline Average & 17.6 & 21.4 & -0.094 & 16.5 & 20.2 & -0.094 \\
\hline More & 20.6 & 20.9 & -0.008 & 21.5 & 27.7 & -0.144 \\
\hline Most deprived & 23.5 & 15.3 & 0.209 & 22.3 & 16.8 & 0.14 \\
\hline \multicolumn{7}{|c|}{ Type 2 diabetes (yrs), mean (SD) } \\
\hline Diabetes duration & $14.15(7.7)$ & $15.12(8.4)$ & -0.125 & $13.97(7.8)$ & $14.89(7.6)$ & -0.117 \\
\hline Insulin duration & $7.36(4.9)$ & $8.01(5.5)$ & -0.130 & $7.3(4.8)$ & $8.68(5.5)$ & -0.287 \\
\hline \multicolumn{7}{|l|}{ Clinical parameters, mean (SD) } \\
\hline Weight (kg) & $127.3(30.3)$ & $90.79(20.6)$ & 1.204 & $123.22(28.3)$ & $114.88(24.5)$ & 0.294 \\
\hline Height (m) & $1.7(0.1)$ & $1.68(0.1)$ & 0.201 & $1.7(0.1)$ & $1.69(0.1)$ & 0.102 \\
\hline BMI $\left(\mathrm{kg} / \mathrm{m}^{2}\right)$ & $43.87(10.0)$ & $32.37(7.5)$ & 1.150 & $42.77(9.6)$ & $40.6(9.0)$ & 0.226 \\
\hline $\mathrm{HbA1c}(\mathrm{mmol} / \mathrm{mol})$ & $72.34(19.3)$ & $70.03(17.2)$ & 0.119 & $72.41(18.6)$ & $70.91(17.9)$ & 0.080 \\
\hline Fasting glucose (mmol/L) & $9.83(4.3)$ & 9.93 (3.9) & -0.023 & $9.84(4.3)$ & 9.82 (3.9) & 0.004 \\
\hline Blood glucose (mmol/L) & $12.22(8.8)$ & $11.69(5.3)$ & 0.071 & $12.04(9.1)$ & $11.92(5.3)$ & 0.016 \\
\hline $\mathrm{SBP}(\mathrm{mmHg})$ & $134.64(14.6)$ & $138.89(16.5)$ & -0.271 & $135.06(14.5)$ & $136.4(16.0)$ & -0.088 \\
\hline $\mathrm{DBP}(\mathrm{mmHg})$ & $78.66(8.4)$ & $78.94(9.6)$ & -0.031 & $79.3(8.5)$ & $78.77(9.3)$ & 0.058 \\
\hline Albumin (g/dL) & $3.96(0.4)$ & $4.15(0.5)$ & -0.368 & $3.96(0.4)$ & $3.96(0.4)$ & -0.005 \\
\hline Alkaline Phosphatase (IU/L) & $98.31(47.1)$ & $91.62(43.0)$ & 0.146 & $98.79(48.8)$ & $96.88(51.5)$ & 0.038 \\
\hline Serum creatinine $(\mu \mathrm{mol} / \mathrm{L})$ & $91.74(78.4)$ & $92.68(52.6)$ & -0.014 & $92.29(84.0)$ & $88.17(57.7)$ & 0.056 \\
\hline C-reactive protein (mg/L) & $10.02(11.4)$ & 14.23 (25.9) & -0.208 & $10.15(11.7)$ & $10.07(16.3)$ & 0.006 \\
\hline Globulin serum (g/L) & $30.98(5.4)$ & $29.93(4.6)$ & 0.206 & $30.87(5.3)$ & $30.73(4.8)$ & 0.027 \\
\hline Packed Cell Volume (L/L) & $0.39(0.04)$ & $0.4(0.05)$ & -0.142 & $0.39(0.04)$ & $0.39(0.06)$ & 0.003 \\
\hline Platelets count $\left(10^{9} / \mathrm{L}\right)$ & $252.88(99.4)$ & $\begin{array}{l}233.21 \\
(101.2)\end{array}$ & 0.197 & $\begin{array}{l}250.29 \\
(100.3)\end{array}$ & $\begin{array}{l}243.03 \\
(111.5)\end{array}$ & 0.069 \\
\hline Triglyceride (mmol/L) & $2.33(1.5)$ & $2.03(1.3)$ & 0.2 & $2.34(1.6)$ & $2.26(1.4)$ & 0.049 \\
\hline Total cholesterol (mmol/L) & $4.47(1.2)$ & $4.49(1.1)$ & -0.019 & $4.52(1.2)$ & $4.52(1.2)$ & 0.002 \\
\hline $\begin{array}{l}\text { Low density lipoprotein } \\
\text { (mmol/L) }\end{array}$ & $2.39(0.9)$ & $2.39(0.9)$ & 0.001 & $2.39(0.9)$ & $2.44(1.0)$ & -0.05 \\
\hline $\begin{array}{l}\text { High density lipoprotein } \\
\text { (mmol/L) }\end{array}$ & $1.07(0.3)$ & $1.22(0.4)$ & -0.439 & $1.07(0.3)$ & $1.1(0.3)$ & -0.091 \\
\hline \multicolumn{7}{|l|}{ Alcohol status, \% } \\
\hline Unknown & 3.7 & 3.1 & 0.03 & 3.3 & 3.0 & 0.017 \\
\hline Ex-drinker & 11.8 & 7.0 & 0.162 & 11.6 & 11.5 & 0.003 \\
\hline Never & 33.1 & 31.3 & 0.039 & 33.1 & 33.1 & -0.002 \\
\hline Current & 51.5 & 58.5 & -0.143 & 52.1 & 52.4 & -0.006 \\
\hline
\end{tabular}


Smoking status, \%

\begin{tabular}{lllllll} 
Ex-smoker & 33.1 & 37.1 & -0.085 & 31.4 & 36.9 & -0.116 \\
Never & 52.9 & 49.7 & 0.064 & 52.9 & 52.2 & 0.015 \\
Current & 14.0 & 13.1 & 0.025 & 15.7 & 10.9 & 0.141 \\
Comorbidities, \% & & & & & \\
AMI & 24.3 & 20.3 & 0.095 & 23.1 & 20.2 & 0.073 \\
Stroke & 11.0 & 12.9 & -0.059 & 12.4 & 7.7 & 0.156 \\
CHD & 77.9 & 75.6 & 0.055 & 78.5 & 72.9 & 0.132 \\
HF & 18.4 & 17.8 & 0.016 & 17.4 & 18.5 & -0.029 \\
PAD & 18.4 & 14.6 & 0.101 & 18.2 & 11.3 & 0.195 \\
\hline
\end{tabular}

Diabetes duration is time from first diagnosis of diabetes to date of intensification with insulin drug (index date).

* Standardised differences are the absolute difference in means or percentages divided by the SD of the treated group. Resulting standardised difference after 1:6 matching based on average treatment effect on treated propensity score technique and robust variance estimation.

† Mean of standardized difference after matching (0.081), i.e. at $8 \%$ difference measured between the matched groups. 
Table 2. Non-fatal cardiovascular events, crude incidence rates and hazard ratios of events in the matched groups.

\begin{tabular}{|c|c|c|}
\hline & Non-bariatric ( $N=579$ ) & Bariatric $(N=131)$ \\
\hline \multicolumn{3}{|l|}{ AMI } \\
\hline No of events/person-years & $95 / 1084$ & $13 / 153$ \\
\hline Absolute rates ${ }^{\mathrm{a}}(95 \% \mathrm{Cl})$ & $87.6(71.6-107.1)$ & $84.9(49.0-146.2)$ \\
\hline $\operatorname{HR}^{b}(95 \% \mathrm{Cl})$ & 1 (reference) & $1.03(0.57-1.86)$ \\
\hline $\operatorname{aHR}^{c}(95 \% \mathrm{Cl})$ & 1 (reference) & $0.98(0.54-1.77)$ \\
\hline \multicolumn{3}{|l|}{ Stroke } \\
\hline No of events/person-years & $40 / 547$ & $8 / 137$ \\
\hline Absolute rates $(95 \% \mathrm{Cl})$ & $73.0(53.5-99.6)$ & $58.2(29.1-116.4)$ \\
\hline $\mathrm{HR}(95 \% \mathrm{Cl})$ & 1 (reference) & $0.77(0.34-1.72)$ \\
\hline aHR $(95 \% \mathrm{Cl})$ & 1 (reference) & $0.87(0.36-2.10)$ \\
\hline \multicolumn{3}{|l|}{$\mathrm{CHD}$} \\
\hline No of events/person-years & $259 / 4446$ & $18 / 840$ \\
\hline Absolute rates $(95 \% \mathrm{Cl})$ & $58.2(51.6-65.8)$ & $21.4(13.5-34.0)$ \\
\hline $\mathrm{HR}(95 \% \mathrm{Cl})$ & 1 (reference) & $0.31(0.19-0.52)$ \\
\hline $\operatorname{aHR}(95 \% \mathrm{Cl})$ & 1 (reference) & $0.29(0.16-0.52)$ \\
\hline \multicolumn{3}{|l|}{$\mathrm{HF}$} \\
\hline No of events/person-years & $91 / 1327$ & $13 / 205$ \\
\hline Absolute rates $(95 \% \mathrm{Cl})$ & $68.6(55.8-84.2)$ & $63(36.9-109.5)$ \\
\hline $\mathrm{HR}(95 \% \mathrm{Cl})$ & 1 (reference) & $0.81(0.44-1.49)$ \\
\hline $\operatorname{aHR}(95 \% \mathrm{Cl})$ & 1 (reference) & $0.89(0.47-1.70)$ \\
\hline \multicolumn{3}{|l|}{ PAD } \\
\hline No of events/person-years & $53 / 718$ & $6 / 231$ \\
\hline Absolute rates $(95 \% \mathrm{Cl})$ & $73.9(56.4-96.7)$ & $25.9(11.6-57.6)$ \\
\hline $\mathrm{HR}(95 \% \mathrm{Cl})$ & 1 (reference) & $0.27(0.09-0.74)$ \\
\hline $\operatorname{aHR}(95 \% \mathrm{Cl})$ & 1 (reference) & $0.31(0.11-0.89)$ \\
\hline
\end{tabular}


Figure 1. Cardiovascular Kaplan-Meier survival analysis plot for the matched cohort throughout 10 years of follow-up.
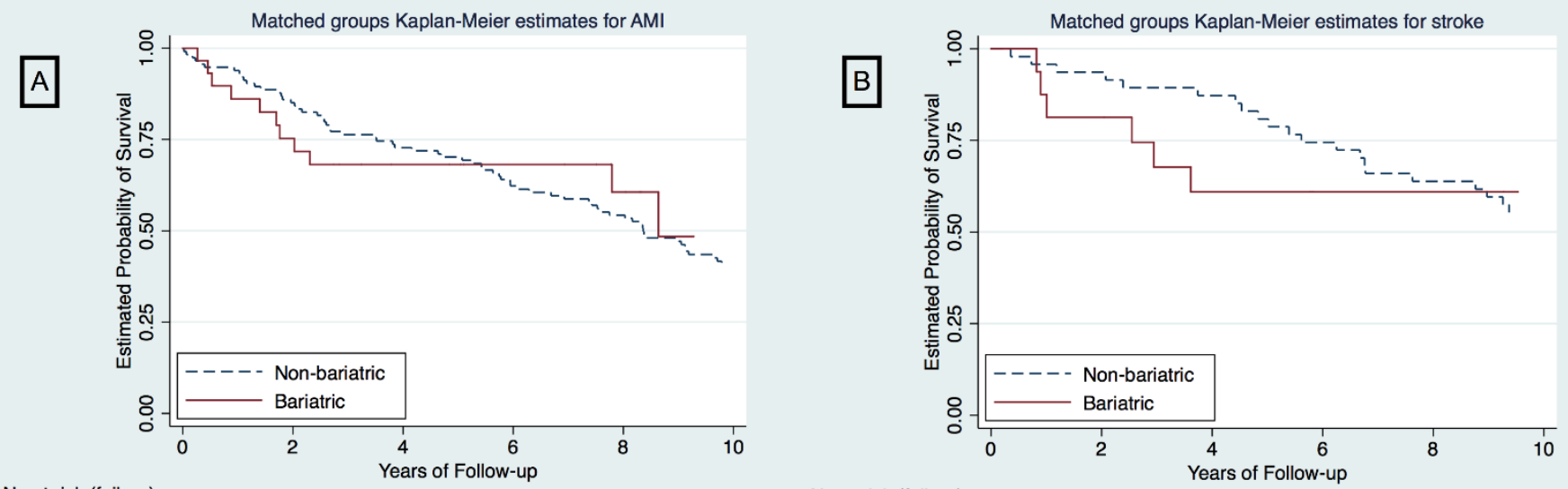

No at risk (failure)

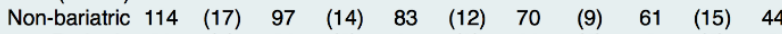

$\begin{array}{lllllllll}\text { Bariatric } 30 & \text { (7) } 21 & \text { (2) } 15 & \text { (0) } 12 & \text { (1) } 8 & \text { (1) } 3\end{array}$

No at risk (failure)

$\begin{array}{rllllclclclc}\text { Non-bariatric } & 47 & (3) & 44 & (3) & 41 & (6) & 35 & (5) & 30 & (4) & 26 \\ \text { Bariatric } & 16 & (3) & 13 & (3) & 9 & (0) & 7 & (0) & 7 & (0) & 5\end{array}$
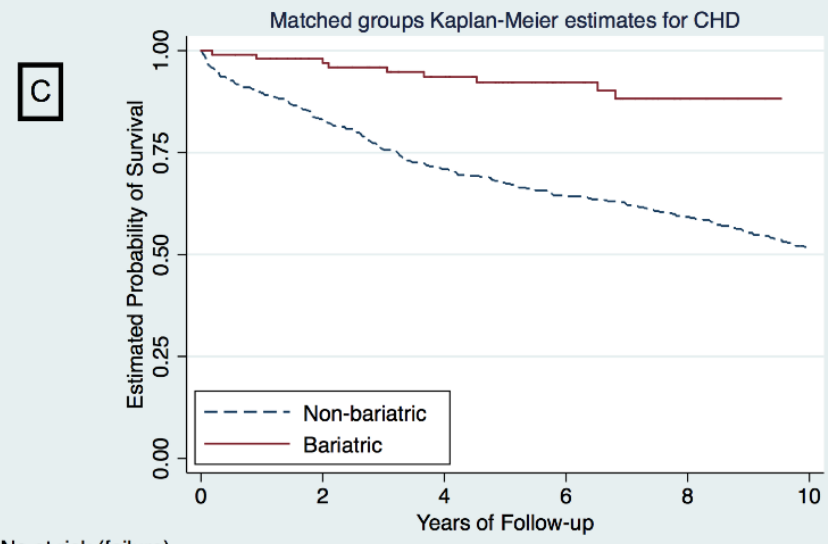

No at risk (failure) $\begin{array}{rccccccccccc}\text { Non-bariatric } & 423 & (73) & 350 & (50) & 300 & (27) & 269 & (22) & 245 & (31) & 206 \\ \text { Bariatric } & 103 & (3) & 91 & (3) & 76 & (1) & 49 & (2) & 34 & (0) & 27\end{array}$

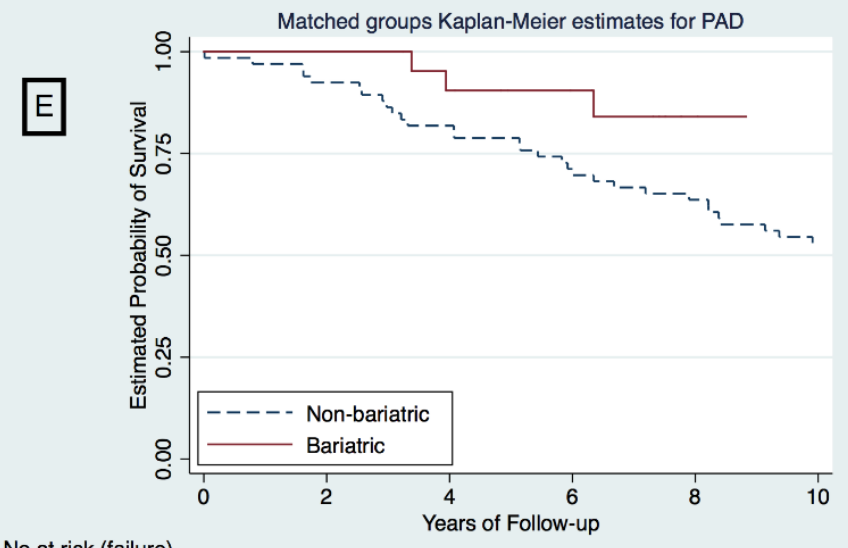

No at risk (failure)

$\begin{array}{rlllllllllll}\text { Non-bariatric } & 66 & (5) & 61 & (7) & 54 & (7) & 47 & (5) & 42 & (7) & 35 \\ \text { Bariatric } & 22 & (0) & 22 & (2) & 19 & (0) & 15 & (1) & 9 & (0) & 7\end{array}$

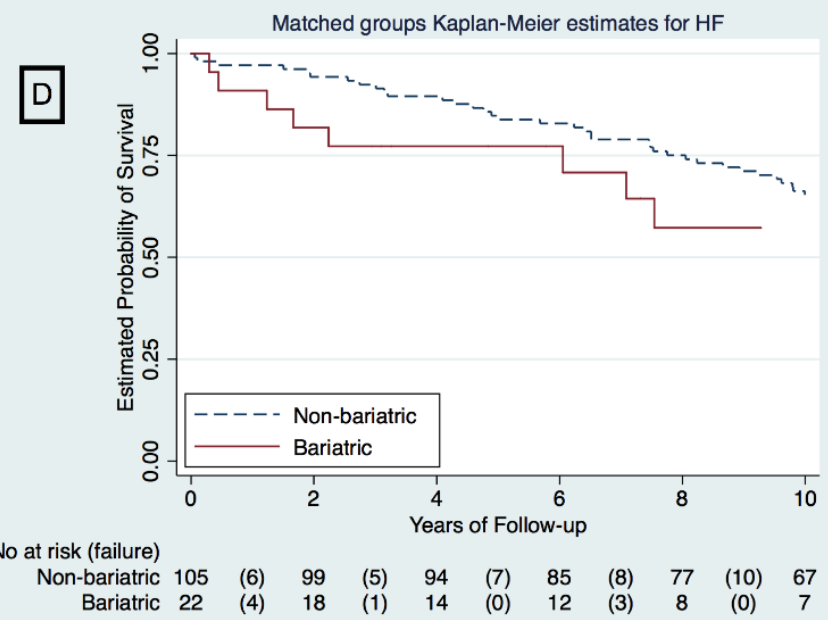

$\begin{array}{rccccccccccc}\text { Non-bariatric } & 105 & (6) & 99 & (5) & 94 & (7) & 85 & (8) & 77 & (10) & 67 \\ \text { Bariatric } & 22 & (4) & 18 & (1) & 14 & (0) & 12 & (3) & 8 & (0) & 7\end{array}$ 
Figure 2. Mean difference in reduction in weight and health outcome variables between the matched groups throughout 10 years of follow-up compared to baseline.

A Change in weight
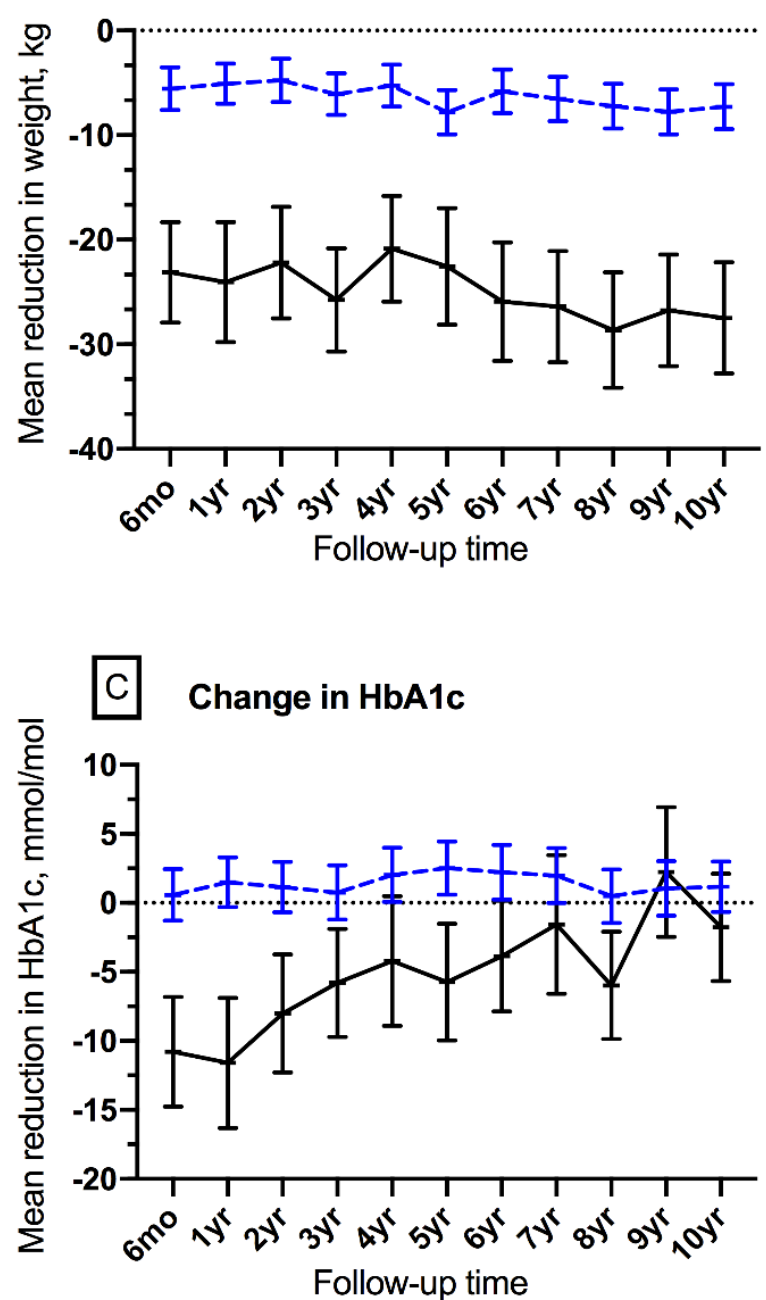

Follow-up time

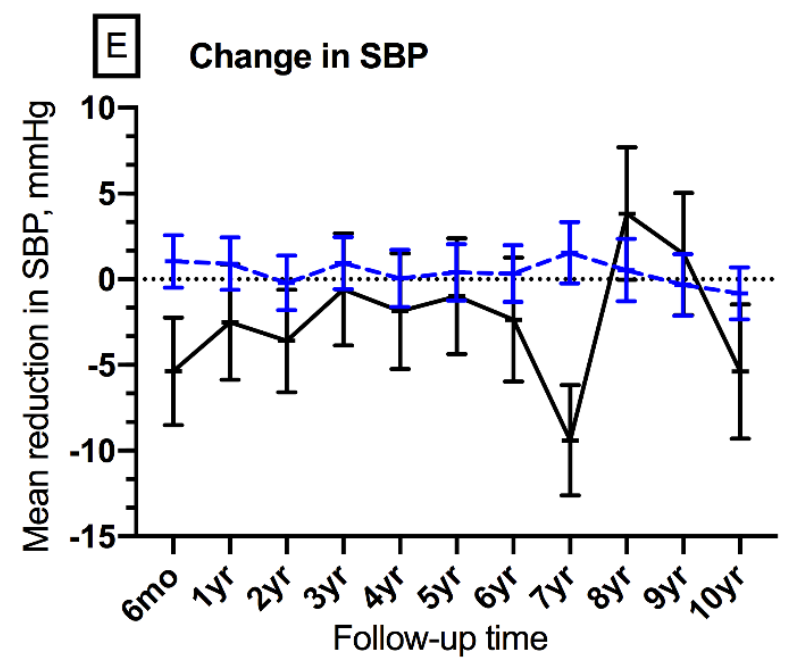

$B$ Change in BMI
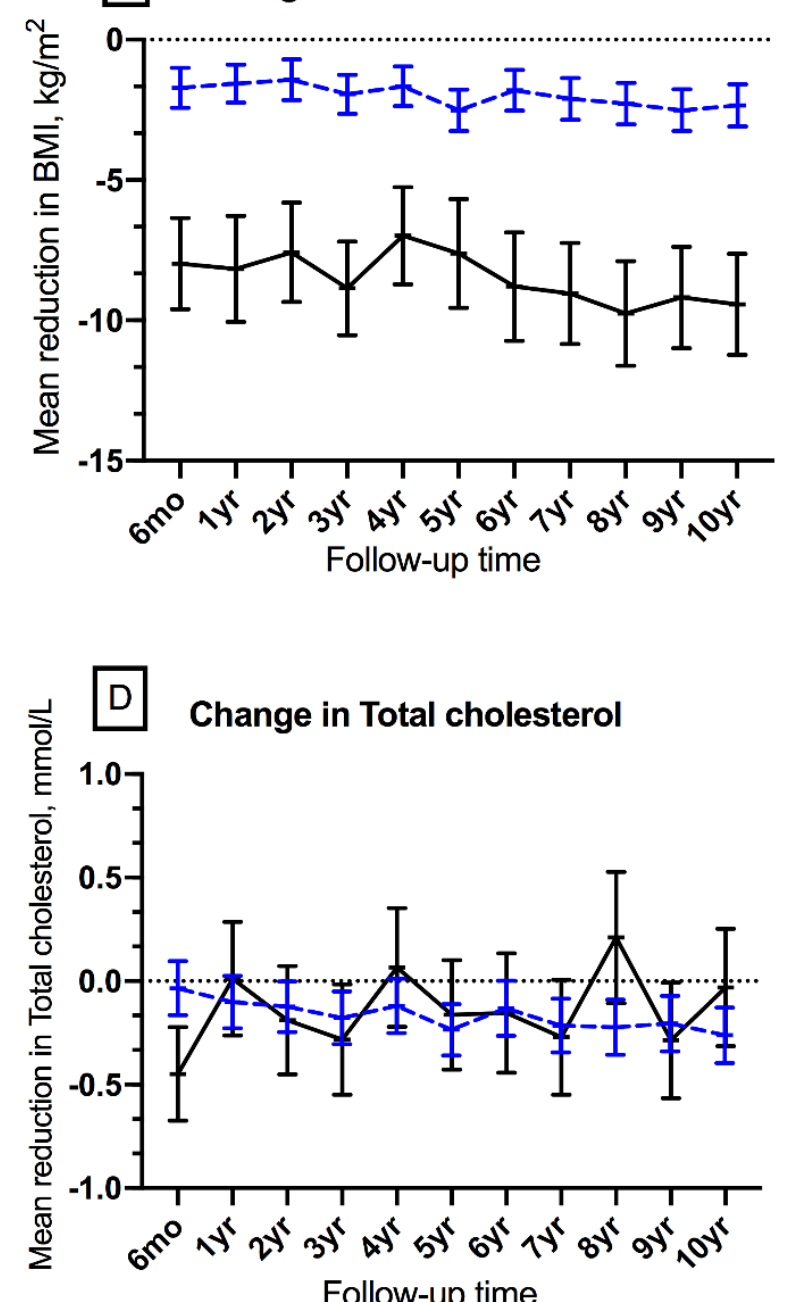

Follow-up time

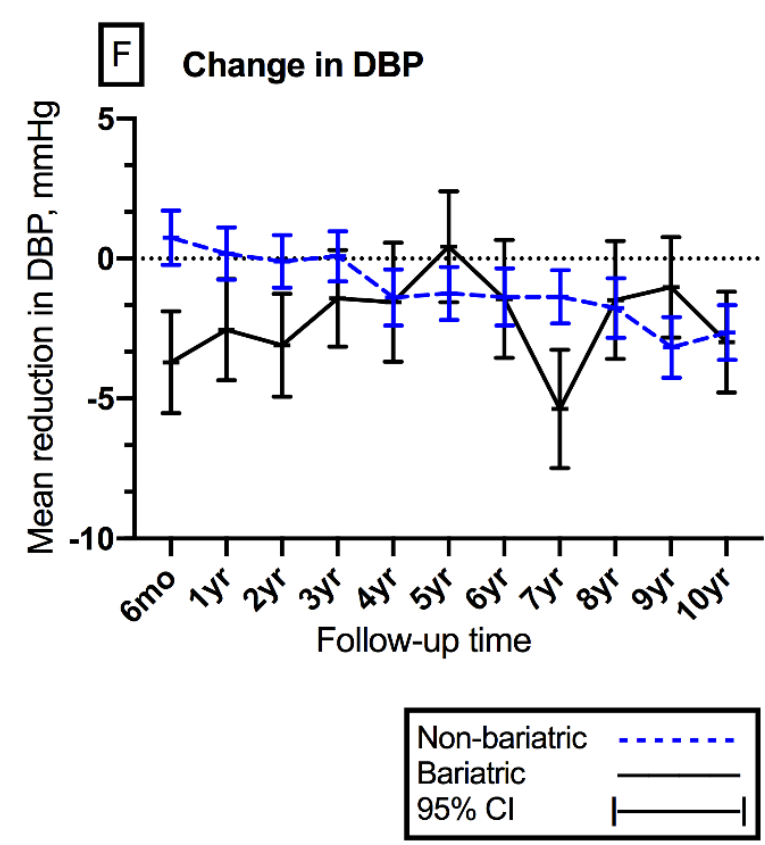




\section{Title}

Effect of Bariatric Surgery on Cardiovascular Events and Metabolic Outcomes In Obese Patients with Insulin-treated Type 2 Diabetes: A Retrospective Cohort Study

${ }^{1}$ Division of Medical Sciences \& Graduate Entry Medicine, School of Medicine, University of Nottingham, Derby, UK, ${ }^{2}$ Faculty of Public Health, College of Health, The Saudi Electronic University, Riyadh, Saudi Arabia, *Correspondent

\section{Conflicts of interest: $\underline{\text { None }}$}




\section{Abstract}

Aims: To compare non-fatal cardiovascular (CV) events and metabolic outcomes, among obese patients with insulin-treated type 2 diabetes who underwent bariatric surgery compared to a propensity matched non-bariatric cohort.

Methods: A retrospective cohort study was conducted among 11,125 active patients with type 2 diabetes from The Health Improvement Network (THIN) database. Propensity score matching (1:6 ratio) was used to identify patients who underwent bariatric surgery $(\mathrm{N}=131)$ with a non-bariatric cohort $(\mathrm{N}=579)$. Follow-up was undertaken for 10 years $(9,686$ personyears) to compare differences in metabolic outcomes and CV risk events that included: Acute Myocardial Infarction (AMI), stroke, Coronary Heart Disease (CHD), Heart Failure (HF) and Peripheral Artery Disease (PAD). Cox proportional regression was used to compute the outcomes between groups.

Results: Mean age was $52 \pm 13$ years ( $60 \%$ female); baseline weight and BMI were $116 \pm 25 \mathrm{~kg}$ and $41 \pm 9 \mathrm{~kg} / \mathrm{m}^{2}$, respectively. Significant reductions in weight and BMI were observed in bariatric and non-bariatric cohorts during 10 years of follow-up. Bariatric surgery had a significant cardio-protective effect by reducing the risk of non-fatal CHD (adjusted hazard ratio [aHR]: 0.29, 95\% Cl:0.16-0.52, p<0.001) and PAD events (aHR: 0.31; 95\% Cl:0.11-0.89; $p=0.03$ ). However, surgery had no significant effect on AMI (aHR:0.98, p=0.95), stroke $(H R: 0.87, p=0.76)$ and $H F(H R: 0.89, p=0.73)$ risks. Bariatric surgery had favourable effects on insulin-independence, $\mathrm{HbA} 1 \mathrm{c}$ and $\mathrm{BP}$.

Conclusion: Among obese insulin-treated patients with type 2 diabetes, bariatric surgery is associated with significant reductions in non-fatal CHD and PAD events, lower body weight, $\mathrm{BP}$, and a greater likelihood of insulin independence during 10 years of follow-up. 
What is already known about this subject?

- Obesity and type 2 diabetes are associated with high risk of cardiovascular events

- Obesity is causally associated with peripheral artery disease

- Insulin -treated type 2 diabetes is associated with additional excess risk of cardiovascular events

- Bariatric surgery in people with or without diabetes reduces cardiovascular events

What does this study add?

- This study focuses on insulin treated type 2 diabetes - recently recognised to be associated with higher risks of cardiovascular events

- Among insulin treated type 2 diabetes, bariatric surgery is associated with significant reduction in non-fatal coronary heart disease and peripheral artery disease

- Among insulin treated type 2 diabetes, bariatric surgery is associated with significant reduction and maintenance of weight loss, significant reduction in $\mathrm{HbA1c}$, with relapse of $\mathrm{HbA1c}$ levels after 6 years of follow up and significant increase of insulin independence

How might this impact on clinical practice?

- Bariatric surgery should be considered as a genuine therapeutic option for the management of obese insulin treated type 2 diabetes to reduce coronary heart disease, peripheral artery disease events, reduce $\mathrm{HbA1c}$ levels and potentially reduce long-term risk of microvascular complications of diabetes as well as inducing insulin indepence. 


\section{Background}

Obesity and Type 2 diabetes (T2D) are major global health problems that are intrinsically linked with adverse cardiovascular (CV) outcomes ${ }^{1,2}$. Obesity-associated coronary artery disease and myocardial dysfunction have been shown to be a direct consequence of excess dysfunctional adipose tissue, driven by increased pro-inflammatory state, insulin resistance, endothelial dysfunction and the development of myocardial hypertrophy ${ }^{3}$. Consequently, weight loss by any means has been shown to improve CV outcomes ${ }^{4}$. Although diet and exercise play a crucial role in obesity management, lifestyle alone may not achieve durable weight loss in the majority of patients ${ }^{5}$. Bariatric surgery therefore has emerged as the most effective and durable strategy for long-term weight loss in morbidly obese individuals ${ }^{6}$. The two most commonly performed bariatric surgical procedures are the Roux-en-Y gastric bypass (RYGB) and sleeve gastrectomy (SG). Indeed, previous studies have shown beneficial effects of these bariatric surgical procedures on CV outcomes ${ }^{7-9}$.

Many patients with T2D will require insulin treatment to manage hyperglycaemia, to reduce the risk of long-term vascular complications ${ }^{10}$. However, insulin therapy is known to induce $\sim 4-9 \mathrm{~kg}$ weight gain in the first year of treatment, while escalation of insulin treatment doses are associated with greater weight gain ${ }^{11}$ and excess CV risk ${ }^{12}$. Furthermore, evidence from randomized controlled trial and observational studies have implicated insulin therapy in patients with T2D with increased CV risk and mortality ${ }^{13-16}$, possibly due to weight gain, recurrent hypoglycaemia and iatrogenic hyperinsulinemia ${ }^{17,18}$. Thus, a cohort of insulintreated patients with T2D, represent a complex heterogenous, challenging group of patients, many of whom have significant comorbidities and high CV disease risk. No studies have assessed the effect bariatric surgery on cardiovascular outcomes among insulin-treated patients with T2D in routine clinical care. 


\section{Methods}

\section{Study design, data sources and study population}

This was a retrospective cohort study that used The Health Improvement Network (THIN), an anonymised health care records derived from over 600 UK general practices, containing details on demographics, lifestyle characteristics, major medical and surgical conditions, drug utilisation, and health outcomes of over 17 million patients, 3.1 million of which are active patients ${ }^{19}$. Our dataset contains all adult patients (age $>18$ years) with T2D and have been prescribed with any form of insulin therapy up to September $2017(\mathrm{~N}=11,125)$. Patients' index date was either the day of bariatric surgery (RYGB or SG) or, in case they have not received bariatric surgery, first intensification of insulin therapy. We excluded patients with type 1 diabetes or non- insulin-treated T2D. Ethics approval was provided by the NHS South East Multi-centre Research Ethics Committee (MREC).

\section{Exposure and outcomes}

Exposure of interest is bariatric surgery (RYGB or SG). Patients were censored throughout 10 years of follow-up - following the development of primary outcome, transferred out, loss to follow-up or at the end of the study. Primary outcome was patients' survivability against nonfatal CV events with further stratification to include CV events into divisions of time to the risk of Acute Myocardial Infarction (AMI), stroke, Coronary Heart Disease (CHD), Heart Failure (HF) and Peripheral Artery Disease (PAD). Secondary outcomes included health covariates such as body weight, calculated BMI, HbA1c, total cholesterol, systolic/diastolic blood pressure and insulin independence.

\section{Covariates and follow-up strategy}

We followed-up the treatment group whom underwent bariatric surgery and compared with their propensity-matched (PS) matched non-bariatric surgery from their first insulin prescription date up to the endpoint of 10-year of follow-up. Patients with CV events prior to the designated baseline point were excluded from the primary survival estimation on each stratified CV element. Baseline clinical parameters (average values from multiple entries) were measured at the same time window according to patient's treatment category, i.e. 90 
days up to one day before the surgery date or first intensification of insulin therapy. Covariates were, then, recalculated at 6-month, and at each year point up to 10 years of follow-up; with 90 days window on every concurring point of time.

\section{Statistical analysis}

Primary analysis was time to the risk of stratified non-fatal CV events that included AMI, stroke, CHD, HF and PAD in a PS-matched groups. The PS model was estimated by using logistic regression model to adjust for baseline characteristics, thus, minimising allocation bias between groups. The balance assessment was made between bariatric (treated) and nonbariatric (untreated) groups by measuring standardised differences before and after the matching procedure. The mean form continuous covariates and proportion of categorical variables between groups were examined and summarised. Each treatment subject was matched to six reference subjects at the nearest distance measured by the estimated PS, based on the estimated treatment probabilities ${ }^{20}$. We employed caliper width $=0.05$ of the standard deviation of the logit of the PS to minimise distance within matched sets which may improve match quality but would limit excessive number of matched subjects ${ }^{21}$. A caliper width of $<0.2$ has been shown to result in optimal estimation compared to higher choices of caliper use ${ }^{22}$. PS was included in all Cox proportional hazards regression modelling as it was considered a prognostic covariate. Stratified log-rank test, with Kaplan-Meier survival curves respectively was used to compare the equality between the PS-matched groups. The absolute reduction in the probability of an event occurring within 10-year follow-up was calculated. Marginal hazard ratios were estimated to quantify the adjusted hazard of an event occurred in the bariatric group compared to the matched non-bariatric group. Proportional hazards assumptions were confirmed through Schoenfeld residuals test. Point estimates with $95 \%$ Confidence Intervals ( $\mathrm{Cls}$ ) at the conventional statistical significance level of 0.05 were used in the regression models. The proportional hazards assumption was examined by comparing the cumulative hazard plots grouped on exposure; no violations were observed.

Missing data among covariates were managed through multiple imputations using the predictive means matching for continuous covariates with accounting to exposure (i.e. bariatric), age, gender, diabetes duration, Townsend deprivation status, marital status, 
smoking and alcohol use ${ }^{23}$. To test the adequacy of our multiple imputation approach in addressing the impact of some missing data, we conducted a sensitivity analysis wherein the primary endpoints in the imputed dataset and were compared with the dataset with missing values and found to be similar, thereby affirming the robustness of the imputation method employed before PS matching procedure was performed ${ }^{24}$.

We used Student's t-test to estimate the mean changes in continuous variables (e.g. body weight \& HbA1c) in both PS matched groups throughout 10-year of follow-up compared to their baseline measurements; and Pearson $X^{2}$ to test on the likelihood of being off insulin at 5 and 10 years from the baseline. Statistical significance was put at a p level of 0.05 . To avoid the probability of type II error, the study was powered to 0.8 and the matched sample size of 710 was found to detect a true difference of less than 0.1 between the two groups at $5 \%$ significance level. The study fulfilled the STROBE criteria for reporting observational studies. Throughout, we used SAS Software version 9.4 in the initial dataset management (SAS Institute, Cary, NC); Stata Statistical Software version 15.1 in all carried analysis (StataCorp., College Station, TX); and GraphPad/Prism version 8.0 for visualisation (La Jolla, CA). 


\section{Results}

\section{Patients' characteristics and total follow-up}

From 11,125 patients with insulin-treated T2D, we identified 155 patients who have had bariatric surgical operation. The PS matching procedure allowed 131 bariatric patients to be matched with up to six control subjects. This yielded a total number of 710 PS-matched participants. The median treatment duration was 10.07 years (interquartile range (IQR): 6.1114.31 years). The median follow-up was 8.42 years (IQR: 2.92-14.58 years) representing a total follow-up period of 9,686 person-years.

In the matched cohort, the overall mean of age was 51.7 (SD 12.5) years; $59.6 \%$ were females. The mean body weight, BMI and HbA1c level were 115.7 (SD 25.4) kg, 40.7 (SD 9.2) kg/m² and 71.2 (SD 18.1) $\mathrm{mmol} / \mathrm{mol}$, respectively. The baseline characteristics in both bariatric and nonbariatric groups were compared between the full and matched cohort with their standardised differences shown in Table 1.

\section{Cardiovascular event rates}

The probability of survival for non-fatal CHD was significantly different between matched bariatric and non-bariatric groups at 1 -year (98.0\% vs $89.6 \%)$, 5-year (92.2\% vs $67.6 \%)$ and 10 year (88.2\% vs 51.6\%) of follow-up (log-rank test $p<0.001$ ) (Fig. 1c). A total of 277 (18 vs 259) events were reported with a crude event rate of 52.4 (21.4 vs 58.2) per 1000 person-years (95\% Cl 46.6-58.9). The probability of survival for non-fatal PAD was also significantly different at 5-year (90.5\% vs $78.8 \%$ ) and 10 -year (84.0\% vs 53.1\%) of follow-up (log-rank test $p=0.007$ ) (Fig. 1e). A total of 59 (6 vs 53) events were observed with a crude event rate of 62.1 (25.9 vs 73.8) per 1000 person-year (95\% Cl 48.1-80.2). The probabilities of survival for non-fatal AMI, stroke and HF were with little or no statistical significance between the matched groups throughout 10 years of follow-up (log-rank test $p>0.5)$ (Fig. 1a, 1b \& 1d). Table 2 shows a summary of the events for each of the stratified CV components with absolute event rates.

\section{Risk of cardiovascular disease}


Bariatric surgery was protective against all analysed CV elements in the matched cohort. The risk of non-fatal CHD and PAD in the bariatric group were significantly lower (by $71 \%$ \& 69\%, respectively) compared to the matched non-bariatric group (CHD aHR: $0.29,95 \% \mathrm{Cl} 0.16-0.52$, $p<0.001$; PAD aHR: 0.31, 95\%Cl 0.11-0.89, $p=0.03$ ) adjusted for age, HbA1c level, diabetes duration, oral antidiabetic drug use, diuretics use, antihypertensive drug use, Townsend deprivation status, alcohol use and smoking status. Despite protective tendency against nonfatal AMI, stroke and HF, none of which was found with statistical significance (AMI aHR: 0.98, 95\% $\mathrm{Cl} 0.54-1.77, \mathrm{p}=0.94$; stroke aHR: $0.87,95 \% \mathrm{Cl} 0.36-2.10, \mathrm{p}=0.75 ; \mathrm{HF}$ aHR: $0.89,95 \% \mathrm{Cl}$ 0.47-1.70, $p=0.73$ ) (Table 2).

\section{Changes in metabolic outcomes}

Significant reductions in the matched cohort (i.e. $p<0.001$ ) favouring the bariatric group vs non-bariatric was observed in terms of body weight and BMI throughout all 10 years of followup compared to baseline. Body weight and BMI for bariatric vs non-bariatric were: at 1-year point ( $97.5 \pm 24.2$ vs $109.8 \pm 18.6 \mathrm{~kg} ; 34.2 \pm 9.0$ vs $38.8 \pm 7.4 \mathrm{~kg} / \mathrm{m}^{2}$, respectively), at 5 -year point (98.9 \pm 23.3 vs $107.1 \pm 18.2 \mathrm{~kg} ; 34.8 \pm 9.2$ vs $37.8 \pm 7.3 \mathrm{~kg} / \mathrm{m}^{2}$, respectively), and at 10 -year point (94.1 \pm 20.1 vs $107.6 \pm 17.3 \mathrm{~kg} ; 32.9 \pm 7.7$ vs $38.0 \pm 7.1 \mathrm{~kg} / \mathrm{m}^{2}$, respectively) of follow-up (Fig. 2a \& 2b). The reduction in $\mathrm{HbA1c}$ was statistically significant up to six years of follow-up. At the first year the level of $\mathrm{HbA1c}$ in the bariatric vs non-bariatric $(60.3 \pm 18.2$ vs $72.0 \pm 17.9$ $\mathrm{mmol} / \mathrm{mol})$, at 3-year point $(66.1 \pm 16.8$ vs $71.3 \pm 17.8 \mathrm{mmol} / \mathrm{mol})$ and at 6 -year point $(68.1 \pm 16.9$ vs $72.8 \pm 18.8 \mathrm{mmol} / \mathrm{mol})$. No statistical difference was observed beyond the seventh year in the HbA1c level between the matched groups (Fig. 2c). Total cholesterol was significantly reduced during the first six months of follow-up $(4.12 \pm 0.99 \mathrm{vs} 4.50 \pm 1.14 \mathrm{mmol} / \mathrm{L}$, $p=0.008$ ) (Fig. 2d). Blood pressure was also significantly reduced early following the bariatric surgery. The systolic blood pressure at 6 -month point ( $130 \pm 18$ vs $137 \pm 16 \mathrm{mmHg}, \mathrm{p}<0.001)$ and at 1-year point (133 \pm 17 vs $137 \pm 15 \mathrm{mmHg}, \mathrm{p}=0.07$ ) (Fig. 2e). The diastolic blood pressure was significantly reduced in the bariatric vs non-bariatric $(p<0.05)$ up to two years of followup (6-month: $76 \pm 10$ vs $79 \pm 9$; 1-year: $77 \pm 9$ vs $79 \pm 9$; 2 -year: $76 \pm 10$ vs $79 \pm 10 \mathrm{mmHg}$ ) (Fig. 2f).

Figure 2 represents reduction in the matched cohort of the analysed outcome variables during 10 years of follow-up in comparison to their baseline measurements with $95 \%$ confidence intervals. 
The analysis of the matched groups also revealed that, at one year of follow-up, $6.4 \%$ of whom underwent bariatric surgery were insulin independent compared to $7.9 \%$ non-bariatric with little or no statistical significance of a difference $\left(X^{2}=0.35, p=0.55\right)$. At three years, $31.2 \%$ of bariatric patients were independent from insulin use compared to $17.6 \%$ non-bariatric $\left(X^{2}=10.59, p=0.001\right)$. At six years, $41.5 \%$ of bariatric patients were independent from using insulin compared to $22.2 \%$ non-bariatric $\left(X^{2}=11.47, p=0.001\right)$. At 10 years, $77.5 \%$ of bariatric patients were independent from using insulin compared to $33.7 \%$ non-bariatric $\left(X^{2}=28.71, p\right.$ $<0.0001)$.

\section{Discussion}

This study showed that, among morbidly obese patients with insulin-treated T2D in routine clinical practice, bariatric surgery was associated with a significant $71 \%$ risk reduction in nonfatal CHD and $69 \%$ reduction in PAD events, as well as significant reductions in weight, $\mathrm{HbA1C}$, insulin independence and blood pressure. However, no significant reductions was observed with $\mathrm{AMI}$, stroke and heart failure.

Our findings were similar in pattern with previous observational studies on bariatric surgery with regards to cardiovascular and metabolic benefits ${ }^{7-9}$. Our study however focuses on patients with Insulin-treated T2D - known to be associated with higher risks of cardiovascular events $^{13-16}$. Indeed, a previous study have shown that while bariatric surgery reduces cardiovascular events and mortality, the mortality risk in people with diabetes after bariatric surgery remains $35 \%$ higher than that of the general population. ${ }^{25}$ Our study therefore extends evidence of cardiovascular benefit of bariatric surgery in this patient cohort whose residual CV risk are likely to be higher. Interestingly, a previous study in patients with diabetes reported a reduction in myocardial infarction but no effect was observed on stroke incidence ${ }^{8}$. However, a factor-treatment interaction analysis showed that the effect of bariatric surgery on AMI was greater in participants with higher total cholesterol and triglyceride levels, implying that those with dyslipidemia were the ones who are likely to gain the most benefit. Since our PS-matched cohort have optimal mean LDL-cholesterol and triglyceride levels ( 2.4 and $2.3 \mathrm{mmol} / \mathrm{L})$, respectively due to high use of statin therapy, this may explain the lack of significant reduction 
of AMI in our cohort while highlighting the importance of statin therapy in this patient cohort. Our observation of significant reduction in PAD events within this patient cohort is novel and have major clinical significant. A recent study have concluded that obesity is causally associated with PAD after controlling for potential confounders like hypertension, dyslipidemia and hyperglycemia ${ }^{26}$.

Insulin therapy is known to induce weight gain ${ }^{11}$. Our data showed a major reduction in weight following bariatric surgery, which persisted at 10 years of follow up. While greater significant reduction in weight following bariatric surgery compared with control is anticipated, it is interesting to note that weight loss was also observed in our PS-matched control cohort. This is likely due to concurrent use of GLP-1 analogue in our patient cohort. Evidence of weight loss with GLP-1 as adjunct to insulin treatment has been shown in randomized controlled trials. ${ }^{27,28}$ In addition, we have also reported significant weight loss after 12 months of adding a GLP-1 to insulin therapy in routine clinical practice ${ }^{29}$. Of note, weight loss was not observed in our non- PS-matched control cohort, indicating robust PS matching protocol used in this study analysis (Supplement). The addition of GLP-1 therapy, in combination with use of other novel weight loss antidiabetic regimens like sodium glucose co-tranporter-2 (SGLT-2) inhibitor, as well as significant calorie restriction may also explain the smaller but appreciable percentage of patients who were insulin independence in the PSmatched control cohort, compared with those who underwent bariatric surgery. Interestingly, in contrast to the observed weight loss which persisted over 10 years of followup, the reduction in $\mathrm{HbA1c}$ was statistically significance only up to six years of follow-up postsurgery, with a rise in $\mathrm{HbA1c}$ during further follow-up. Previous studies comparing bariatric surgery outcomes with medical/lifestyle intervention have mainly reported $\mathrm{HbA} 1 \mathrm{c}$ reduction up to five years post surgery ${ }^{30-32}$, albeit in patients with T2D irrespective of treatment regimen. The discordance between long-term weight and HbA1c outcomes suggested that the observed relapse in $\mathrm{HbA} 1 \mathrm{c}$ level was independent of weight regain. Nonetheless, any beneficial effects of bariatric surgery on weight, $\mathrm{HbA} 1 \mathrm{c}$ reduction and insulin independence will have significant impact on the long-term risk of vascular complications of diabetes and will likely confer cost savings to the UK National Health Service in the long-term. 
The main strength of our study derives from the inclusion of a relatively large cohort of insulintreated T2D in a real-world population which can be generalized to the UK or similar population. This implies that our findings will be generalizable to various population with similar demographics. The cohort of patients studied here provides adequate statistical power and also contains information on other time-varying covariates to adjust for possible confounders. We adjusted for a large set of factors that could have differed at the baseline through a robust PS-matching protocol. This is crucial since the decision to have bariatric surgery in routine clinical practice is often based on multiple factors, not confided to UK NICE guidelines. Nevertheless, some residual confounding in our study could persists due to our inability to measure and adjust for the dosage of the insulin therapy as well as the reliability of diabetes duration due to the ongoing issue of identifying incident versus prevalent diabetes. Also, the classification of exposure into two broad types of bariatric surgery could have possibly masked the effects of individual types of bariatric surgery and could have driven our study away or closer to the null hypothesis. Nonetheless, previous high profile studies on cardiovascular benefits of bariatric surgery have not looked at individual types of surgery.

In summary, this study suggests that bariatric surgery in morbidly obese patients with insulintreated T2D is associated with a significant reduction in a non-fatal CHD and PAD events, as well as significant reduction in weight, $\mathrm{HbA} 1 \mathrm{c}$ and insulin independence compared with matched control. The mechanism for this cardio-protective effects remained speculative but further study is required to confirm this observation. 


\section{References}

1 Finucane MM, Stevens GA, Cowan MJ, et al. Global Burden of Metabolic Risk Factors of Chronic Diseases Collaborating Group (Body Mass Index) National, regional, and global trends in body-mass index since 1980: systematic analysis of health examination surveys and epidemiological studies with 960 country-years and 9.1 million participants. Lancet 2011;377:557-567

2 Adams KF, Schatzkin A, Harris TB, et al. Overweight, obesity, and mortality in a large prospective cohort of persons 50 to 71 years old. N Engl J Med 2006;355:763-778

3 Bays HE Adiposopathy is "sick fat" a cardiovascular disease? J Am Coll Cardiol 2011;57:2461-73

$4 \quad$ Vidal J. Updated review on the benefits of weight loss. Int J Obes Relat Metab Disord. 2002;26(Suppl 4):S25-S28

5 Dombrowski SU, Knittle K, Avenell A, Araujo-Soares V, Sniehotta FF. Long term maintenance of weight loss with non-surgical interventions in obese adults: systematic review and meta-analyses of randomised controlled trials. BMJ 2014; 348: g2646

6 Golzarand $\mathrm{M}$, Toolabi K, Farid R. The bariatric surgery and weight losing: a metaanalysis in the long- and very long-term effects of laparoscopic adjustable gastric banding, laparoscopic Roux-en-Y gastric bypass and laparoscopic sleeve gastrectomy on weight loss in adults. Surg Endosc. 2017;31:4331-4345.

7 Eliasson B, Liakopoulos V, Franzén S, Näslund I, Svensson AM, Ottosson J, Gudbjörnsdottir S. Cardiovascular disease and mortality in patients with type 2 diabetes after bariatric surgery in Sweden: a nationwide, matched, observational cohort study. Lancet Diabetes Endocrinol. 2015;3:847-54.

8 Romeo S, Maglio C, Burza MA, Pirazzi C, Sjöholm K, Jacobson P, Svensson PA, Peltonen M, Sjöström L, Carlsson LM. Cardiovascular events after bariatric surgery in obese subjects with type 2 diabetes. Diabetes Care. 2012; 35:2613-7.

9 Vest AR1, Heneghan HM, Agarwal S, Schauer PR, Young JB. Bariatric surgery and cardiovascular outcomes: a systematic review. Heart. 2012; 98:1763-77.

10 Holman RR, Paul SK, Bethel MA, Matthews DR, Neil HA. 10-year follow-up of intensive glucose control in type 2 diabetes. N Engl J Med 2008; 359: 1577-89. 
11 Russell-Jones D, Khan R. Insulin-associated weight gain in diabetes - causes, effects and coping strategies. Diabetes, Obesity and Metabolism 2007; 9(6): 799-812.

12 Herman ME, O'Keefe JH, Bell DSH, Schwartz SS. Insulin Therapy Increases Cardiovascular Risk in Type 2 Diabetes. Prog Cardiovasc Dis. 2017; 60:422-434.

13 The Action to Control Cardiovascular risk in diabetes study Group. Effects of Intensive Glucose lowering in type 2 Diabetes. New England J Med. 2008; 358:2545

14 Holman RR, Sourij H, Califf RM. Cardiovascular outcome trials of glucose-lowering drugs or strategies in type 2 diabetes. Lancet 2014; 383(9933): 2008-17.

15 Currie CJ, Poole CD, Evans M, Peters JR, Morgan CL. Mortality and other important diabetes-related outcomes with insulin vs other antihyperglycemic therapies in type 2 diabetes. J Clin Endocrinol Metab 2013; 98(2): 668-77.

16 Roumie CL, Greevy RA, Grijalva CG, et al. Association between intensification of metformin treatment with insulin vs sulfonylureas and cardiovascular events and allcause mortality among patients with diabetes. Jama 2014; 311(22): 2288-96.

17 Muniyappa R, lantorno M, Quon MJ. An integrated view of insulin resistance and endothelial dysfunction. Endocrinol Metab Clin North Am. 2008; 37:685-711

18 Van Avendonk MWJ, Rutten GEH. Insulin therapy in type 2 diabetes: what is the evidence? Diabetes, Obesity and Metabolism 2009; 11(5):415-432.

19 The Heath Improvement Network (THIN). 2018; Available from: https://www.iqvia.com/locations/uk-and-ireland/thin.

20. Garrido, M.M., et al., Methods for Constructing and Assessing Propensity Scores. Health Services Research, 2014. 49: p. 1701-1720.

21. Rassen, J.A., et al., One-to-many propensity score matching in cohort studies. Pharmacoepidemiology and Drug Safety, 2012. 21(S2): p. 69-80.

22. Austin, P.C., Statistical Criteria for Selecting the Optimal Number of Untreated Subjects Matched to Each Treated Subject When Using Many-to-One Matching on the Propensity Score. American Journal of Epidemiology, 2010. 172: p. 1092-1097.

23. Morris, T.P., I.R. White, and P. Royston, Tuning multiple imputation by predictive mean matching and local residual draws. BMC Medical Research Methodology, 2014. 14: p. 75. 
24. Eulenburg, C., et al., Propensity Scoring after Multiple Imputation in a Retrospective Study on Adjuvant Radiation Therapy in Lymph-Node Positive Vulvar Cancer. PLoS ONE, 2016. 11: p. e0165705.

25 Dhalwani NN, Zaccardi F, Waheed H, Mytton J, Papamargaritis D, Webb DR, Evison F, Lilford R, Davies MJ, Khunti K. Cardiovascular, cancer and mortality events after bariatric surgery in people with and without pre-existing diabetes: A nationwide study. J Diabetes. 2018. doi: 10.1111/1753-0407.12851. [Epub ahead of print]

26 Huang $Y, X u$ M, Xie L, Wang T, Huang X, Lv X, Chen Y, Ding L, Lin L, Wang W, Bi Y, Sun Y, Zhang Y, Ning G. Obesity and peripheral arterial disease: A Mendelian Randomization analysis. Atherosclerosis. 2016;247:218-24.

27 Ekelund M, Filipsson K, Tengmark BO, Sjöberg S, Pehrsson NG. Liraglutide in people treated for type 2 diabetes with multiple daily insulin injections: randomised clinical trial (MDI Liraglutide trial). BMJ. 2015;351:h5364.doi: 10.1136/bmj.h5364.

28 Mathieu C, Rodbard HW, Cariou B, et al; BEGIN: VICTOZA ADD-ON (NN1250-3948) study group. A comparison of adding liraglutide versus a single daily dose of insulin aspart to insulin degludec in subjects with type 2 diabetes (BEGIN: VICTOZA ADD-ON). Diabetes Obes Metab 2014; 16:636-44.

29 Anyanwagu U, Mamza J, Donnelly R, Idris I. Effect of adding GLP-1RA on mortality, cardiovascular events, and metabolic outcomes among insulin-treated patients with type 2 diabetes: A large retrospective UK cohort study. Am Heart J. 2018;196:18-27

30 Schauer PR, Bhatt DL, Kirwan JP, et al.; STAMPEDE Investigators. Bariatric surgery versus intensive medical therapy for diabetes-3-year outcomes. N Engl J Med 2014;370:2002-2013

31 Mingrone G, Panunzi S, De Gaetano A, et al. Bariatric-metabolic surgery versus conventional medical treatment in obese patients with type 2 diabetes: 5 year followup of an open-label, singlecentre, randomised controlled trial. Lancet 2015; 386:964973

32. Ikramuddin S, Korner J, LeeW-J, et al. Rouxen-Y gastric bypass vs intensive medical management for the control of type 2 diabetes, hypertension, and hyperlipidemia: the Diabetes Surgery Study randomized clinical trial. JAMA 2013;309:2240-2249 
Table 1. Baseline characteristics

\begin{tabular}{|c|c|c|c|c|c|c|}
\hline \multirow[b]{3}{*}{ Baseline variable } & \multicolumn{6}{|l|}{ Cohort } \\
\hline & \multicolumn{3}{|c|}{$\begin{array}{l}\text { Full population } \\
{[\mathrm{N}=11,125]}\end{array}$} & \multicolumn{3}{|c|}{$\begin{array}{l}\text { Propensity matched } \\
{[\mathrm{N}=710]}\end{array}$} \\
\hline & $\begin{array}{l}\text { Bariatric } \\
{[n=155]}\end{array}$ & $\begin{array}{l}\text { Non-bariatric } \\
{[n=10,970]}\end{array}$ & Std. diff* & $\begin{array}{l}\text { Bariatric } \\
{[n=131]} \\
\end{array}$ & $\begin{array}{l}\text { Non-bariatric } \\
{[n=579]}\end{array}$ & Std. difft \\
\hline \multicolumn{7}{|l|}{ Demographics } \\
\hline Age (yrs), mean (SD) & $50.01(11.1)$ & $57.71(13.3)$ & -0.694 & $50.74(11.0)$ & $51.96(12.8)$ & -0.110 \\
\hline \multicolumn{7}{|l|}{ Gender, no (\%) } \\
\hline Female & $89(57.4)$ & $5068(46.2)$ & 0.224 & $73(55.4)$ & $351(60.6)$ & -0.107 \\
\hline \multicolumn{7}{|l|}{ Townsend deprivation, \% } \\
\hline Least deprived & 14.0 & 21.7 & -0.204 & 15.7 & 17.3 & -0.044 \\
\hline Less & 24.3 & 20.7 & 0.086 & 24.0 & 18.1 & 0.145 \\
\hline Average & 17.6 & 21.4 & -0.094 & 16.5 & 20.2 & -0.094 \\
\hline More & 20.6 & 20.9 & -0.008 & 21.5 & 27.7 & -0.144 \\
\hline Most deprived & 23.5 & 15.3 & 0.209 & 22.3 & 16.8 & 0.14 \\
\hline \multicolumn{7}{|c|}{ Type 2 diabetes (yrs) , mean (SD) } \\
\hline Diabetes duration & $14.15(7.7)$ & $15.12(8.4)$ & -0.125 & $13.97(7.8)$ & $14.89(7.6)$ & -0.117 \\
\hline Insulin duration & $7.36(4.9)$ & $8.01(5.5)$ & -0.130 & $7.3(4.8)$ & $8.68(5.5)$ & -0.287 \\
\hline \multicolumn{7}{|l|}{ Clinical parameters, mean (SD) } \\
\hline Weight (kg) & $127.3(30.3)$ & $90.79(20.6)$ & 1.204 & $123.22(28.3)$ & $114.88(24.5)$ & 0.294 \\
\hline Height (m) & $1.7(0.1)$ & $1.68(0.1)$ & 0.201 & $1.7(0.1)$ & $1.69(0.1)$ & 0.102 \\
\hline $\mathrm{BMI}\left(\mathrm{kg} / \mathrm{m}^{2}\right)$ & $43.87(10.0)$ & $32.37(7.5)$ & 1.150 & $42.77(9.6)$ & $40.6(9.0)$ & 0.226 \\
\hline $\mathrm{HbA} 1 \mathrm{c}(\mathrm{mmol} / \mathrm{mol})$ & $72.34(19.3)$ & $70.03(17.2)$ & 0.119 & $72.41(18.6)$ & $70.91(17.9)$ & 0.080 \\
\hline Fasting glucose (mmol/L) & $9.83(4.3)$ & 9.93 (3.9) & -0.023 & $9.84(4.3)$ & $9.82(3.9)$ & 0.004 \\
\hline Blood glucose (mmol/L) & $12.22(8.8)$ & $11.69(5.3)$ & 0.071 & $12.04(9.1)$ & $11.92(5.3)$ & 0.016 \\
\hline SBP (mmHg) & $134.64(14.6)$ & $138.89(16.5)$ & -0.271 & $135.06(14.5)$ & $136.4(16.0)$ & -0.088 \\
\hline $\mathrm{DBP}(\mathrm{mmHg})$ & $78.66(8.4)$ & $78.94(9.6)$ & -0.031 & $79.3(8.5)$ & $78.77(9.3)$ & 0.058 \\
\hline Albumin (g/dL) & $3.96(0.4)$ & $4.15(0.5)$ & -0.368 & $3.96(0.4)$ & $3.96(0.4)$ & -0.005 \\
\hline Alkaline Phosphatase (IU/L) & $98.31(47.1)$ & $91.62(43.0)$ & 0.146 & $98.79(48.8)$ & $96.88(51.5)$ & 0.038 \\
\hline Serum creatinine $(\mu \mathrm{mol} / \mathrm{L})$ & $91.74(78.4)$ & $92.68(52.6)$ & -0.014 & $92.29(84.0)$ & $88.17(57.7)$ & 0.056 \\
\hline C-reactive protein (mg/L) & $10.02(11.4)$ & $14.23(25.9)$ & -0.208 & $10.15(11.7)$ & $10.07(16.3)$ & 0.006 \\
\hline Globulin serum (g/L) & $30.98(5.4)$ & $29.93(4.6)$ & 0.206 & $30.87(5.3)$ & $30.73(4.8)$ & 0.027 \\
\hline Packed Cell Volume (L/L) & $0.39(0.04)$ & $0.4(0.05)$ & -0.142 & $0.39(0.04)$ & $0.39(0.06)$ & 0.003 \\
\hline Platelets count $\left(10^{9} / \mathrm{L}\right)$ & $252.88(99.4)$ & $\begin{array}{l}233.21 \\
(101.2)\end{array}$ & 0.197 & $\begin{array}{l}250.29 \\
(100.3)\end{array}$ & $\begin{array}{l}243.03 \\
(111.5)\end{array}$ & 0.069 \\
\hline Triglyceride (mmol/L) & $2.33(1.5)$ & $2.03(1.3)$ & 0.2 & $2.34(1.6)$ & $2.26(1.4)$ & 0.049 \\
\hline Total cholesterol (mmol/L) & $4.47(1.2)$ & 4.49 (1.1) & -0.019 & $4.52(1.2)$ & $4.52(1.2)$ & 0.002 \\
\hline $\begin{array}{l}\text { Low density lipoprotein } \\
\text { (mmol/L) }\end{array}$ & $2.39(0.9)$ & $2.39(0.9)$ & 0.001 & $2.39(0.9)$ & $2.44(1.0)$ & -0.05 \\
\hline $\begin{array}{l}\text { High density lipoprotein } \\
(\mathrm{mmol} / \mathrm{L})\end{array}$ & $1.07(0.3)$ & $1.22(0.4)$ & -0.439 & $1.07(0.3)$ & $1.1(0.3)$ & -0.091 \\
\hline \multicolumn{7}{|l|}{ Alcohol status, \% } \\
\hline Unknown & 3.7 & 3.1 & 0.03 & 3.3 & 3.0 & 0.017 \\
\hline Ex-drinker & 11.8 & 7.0 & 0.162 & 11.6 & 11.5 & 0.003 \\
\hline Never & 33.1 & 31.3 & 0.039 & 33.1 & 33.1 & -0.002 \\
\hline Current & 51.5 & 58.5 & -0.143 & 52.1 & 52.4 & -0.006 \\
\hline
\end{tabular}


Smoking status, \%

\begin{tabular}{lllllll} 
Ex-smoker & 33.1 & 37.1 & -0.085 & 31.4 & 36.9 & -0.116 \\
Never & 52.9 & 49.7 & 0.064 & 52.9 & 52.2 & 0.015 \\
Current & 14.0 & 13.1 & 0.025 & 15.7 & 10.9 & 0.141 \\
Comorbidities, \% & & & & & \\
AMI & 24.3 & 20.3 & 0.095 & 23.1 & 20.2 & 0.073 \\
Stroke & 11.0 & 12.9 & -0.059 & 12.4 & 7.7 & 0.156 \\
CHD & 77.9 & 75.6 & 0.055 & 78.5 & 72.9 & 0.132 \\
HF & 18.4 & 17.8 & 0.016 & 17.4 & 18.5 & -0.029 \\
PAD & 18.4 & 14.6 & 0.101 & 18.2 & 11.3 & 0.195 \\
\hline
\end{tabular}

10 Diabetes duration is time from first diagnosis of diabetes to date of intensification with insulin drug (index date).

* Standardised differences are the absolute difference in means or percentages divided by the SD of the treated group. Resulting standardised difference after 1:6 matching based on average treatment effect on treated propensity score technique and robust variance estimation.

† Mean of standardized difference after matching (0.081), i.e. at $8 \%$ difference measured between the matched groups. 
Table 2. Non-fatal cardiovascular events, crude incidence rates and hazard ratios of events in the matched groups.

\begin{tabular}{|c|c|c|}
\hline & Non-bariatric $(\mathrm{N}=579)$ & Bariatric $(\mathrm{N}=131)$ \\
\hline \multicolumn{3}{|l|}{ AMI } \\
\hline No of events/person-years & $95 / 1084$ & $13 / 153$ \\
\hline Absolute rates ${ }^{\mathrm{a}}(95 \% \mathrm{Cl})$ & $87.6(71.6-107.1)$ & $84.9(49.0-146.2)$ \\
\hline $\mathrm{HR}^{\mathrm{b}}(95 \% \mathrm{Cl})$ & 1 (reference) & $1.03(0.57-1.86)$ \\
\hline $\operatorname{aHR}^{\mathrm{c}}(95 \% \mathrm{Cl})$ & 1 (reference) & $0.98(0.54-1.77)$ \\
\hline \multicolumn{3}{|l|}{ Stroke } \\
\hline No of events/person-years & $40 / 547$ & $8 / 137$ \\
\hline Absolute rates $(95 \% \mathrm{Cl})$ & $73.0(53.5-99.6)$ & $58.2(29.1-116.4)$ \\
\hline $\mathrm{HR}(95 \% \mathrm{Cl})$ & 1 (reference) & $0.77(0.34-1.72)$ \\
\hline $\operatorname{aHR}(95 \% \mathrm{Cl})$ & 1 (reference) & $0.87(0.36-2.10)$ \\
\hline \multicolumn{3}{|l|}{$\mathrm{CHD}$} \\
\hline No of events/person-years & $259 / 4446$ & $18 / 840$ \\
\hline Absolute rates $(95 \% \mathrm{Cl})$ & $58.2(51.6-65.8)$ & $21.4(13.5-34.0)$ \\
\hline HR $(95 \% \mathrm{Cl})$ & 1 (reference) & $0.31(0.19-0.52)$ \\
\hline aHR $(95 \% \mathrm{Cl})$ & 1 (reference) & $0.29(0.16-0.52)$ \\
\hline \multicolumn{3}{|l|}{$\mathrm{HF}$} \\
\hline No of events/person-years & $91 / 1327$ & $13 / 205$ \\
\hline Absolute rates $(95 \% \mathrm{Cl})$ & $68.6(55.8-84.2)$ & $63(36.9-109.5)$ \\
\hline $\mathrm{HR}(95 \% \mathrm{Cl})$ & 1 (reference) & $0.81(0.44-1.49)$ \\
\hline $\operatorname{aHR}(95 \% \mathrm{Cl})$ & 1 (reference) & $0.89(0.47-1.70)$ \\
\hline \multicolumn{3}{|l|}{ PAD } \\
\hline No of events/person-years & $53 / 718$ & $6 / 231$ \\
\hline Absolute rates $(95 \% \mathrm{Cl})$ & 73.9 (56.4-96.7) & $25.9(11.6-57.6)$ \\
\hline $\mathrm{HR}(95 \% \mathrm{Cl})$ & 1 (reference) & $0.27(0.09-0.74)$ \\
\hline aHR $(95 \% \mathrm{Cl})$ & 1 (reference) & $0.31(0.11-0.89)$ \\
\hline
\end{tabular}


Figure 1. Cardiovascular Kaplan-Meier survival analysis plot for the matched cohort throughout 10 years of 1 follow-up.

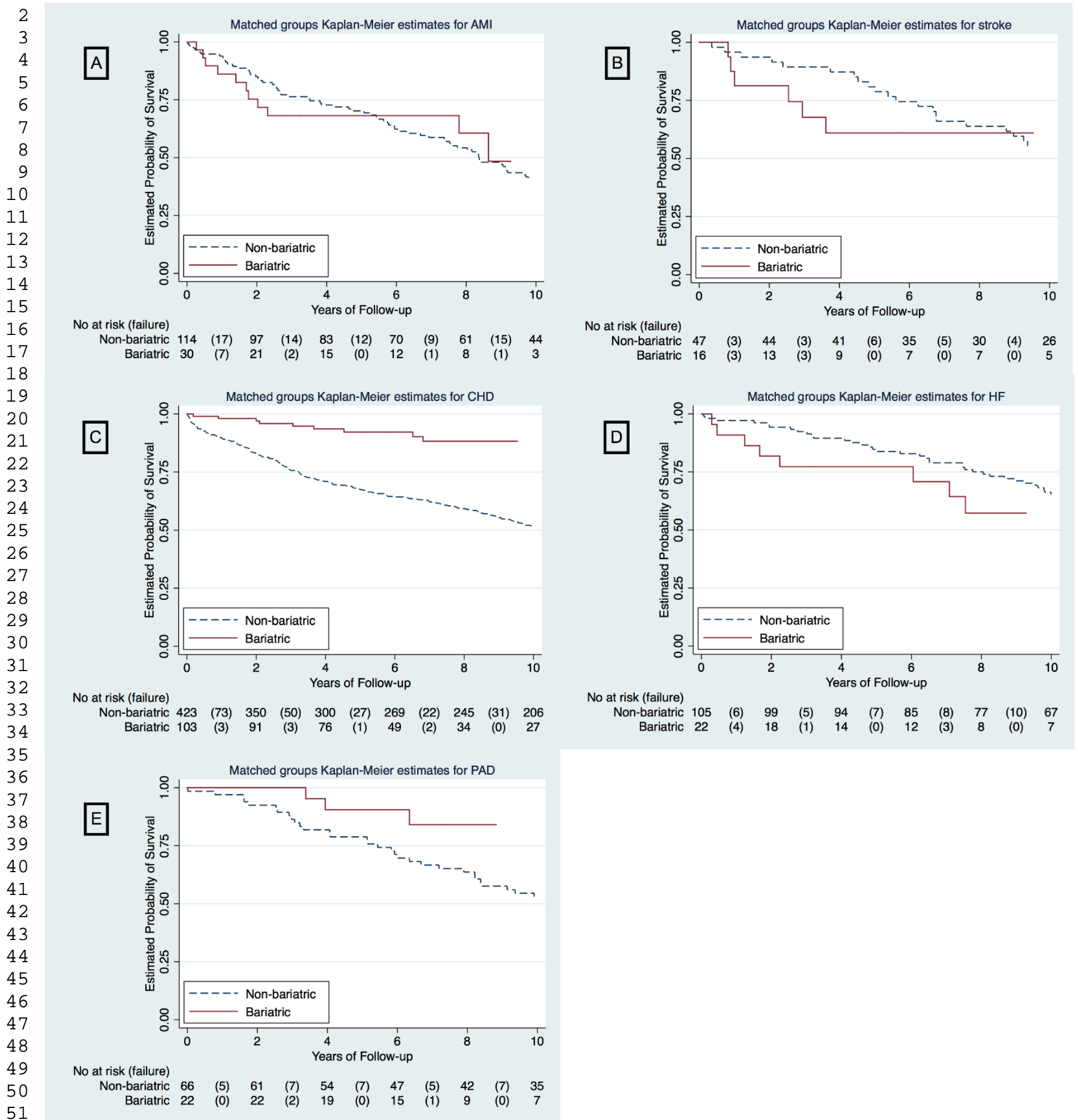


Figure 2. Mean difference in reduction in weight and health outcome variables between the matched groups throughout 10 years of follow-up compared to baseline.

1
A Change in weight
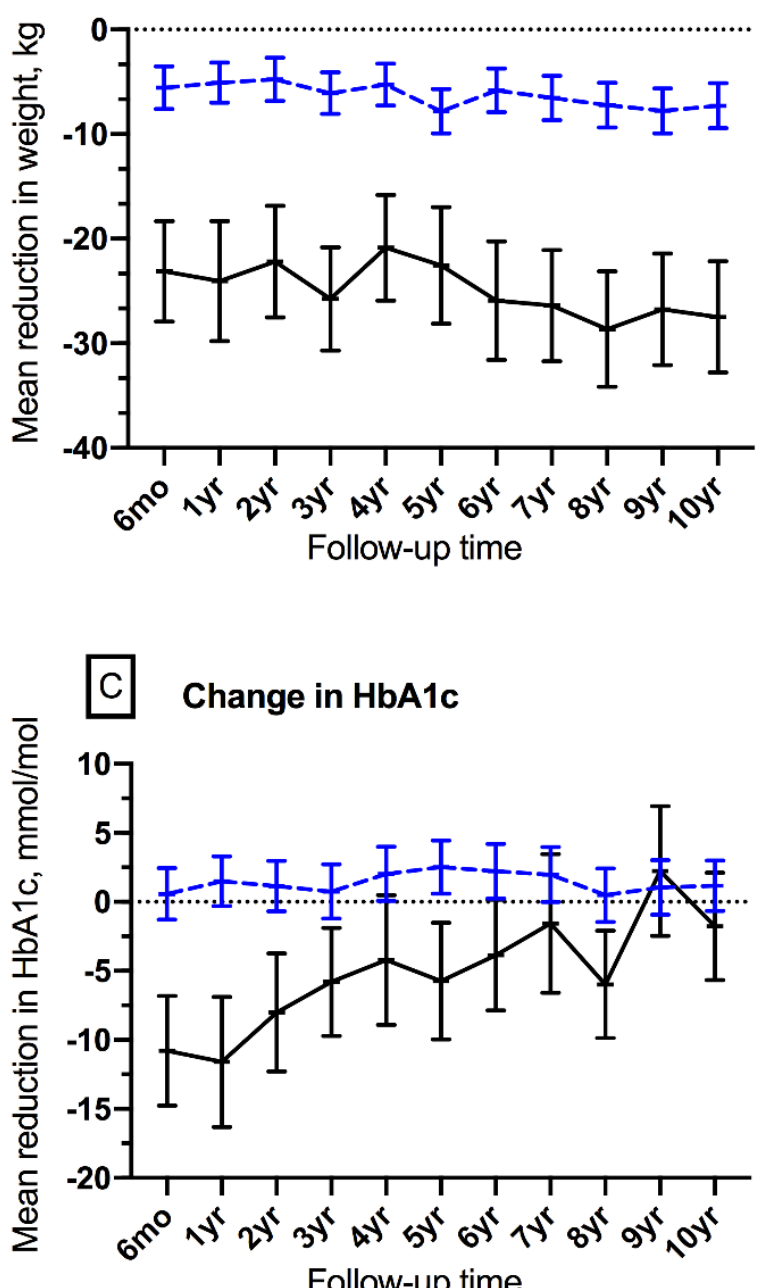

Follow-up time

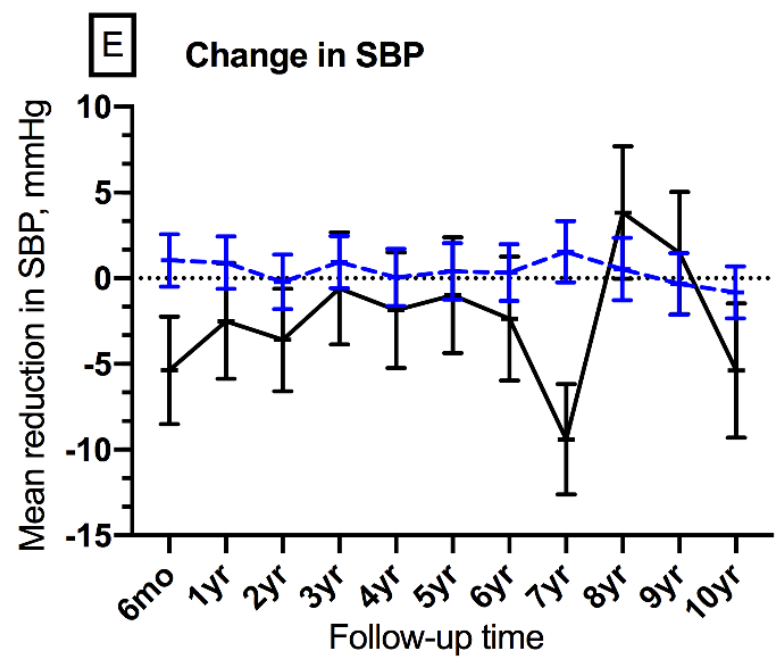

$B$ Change in BMI
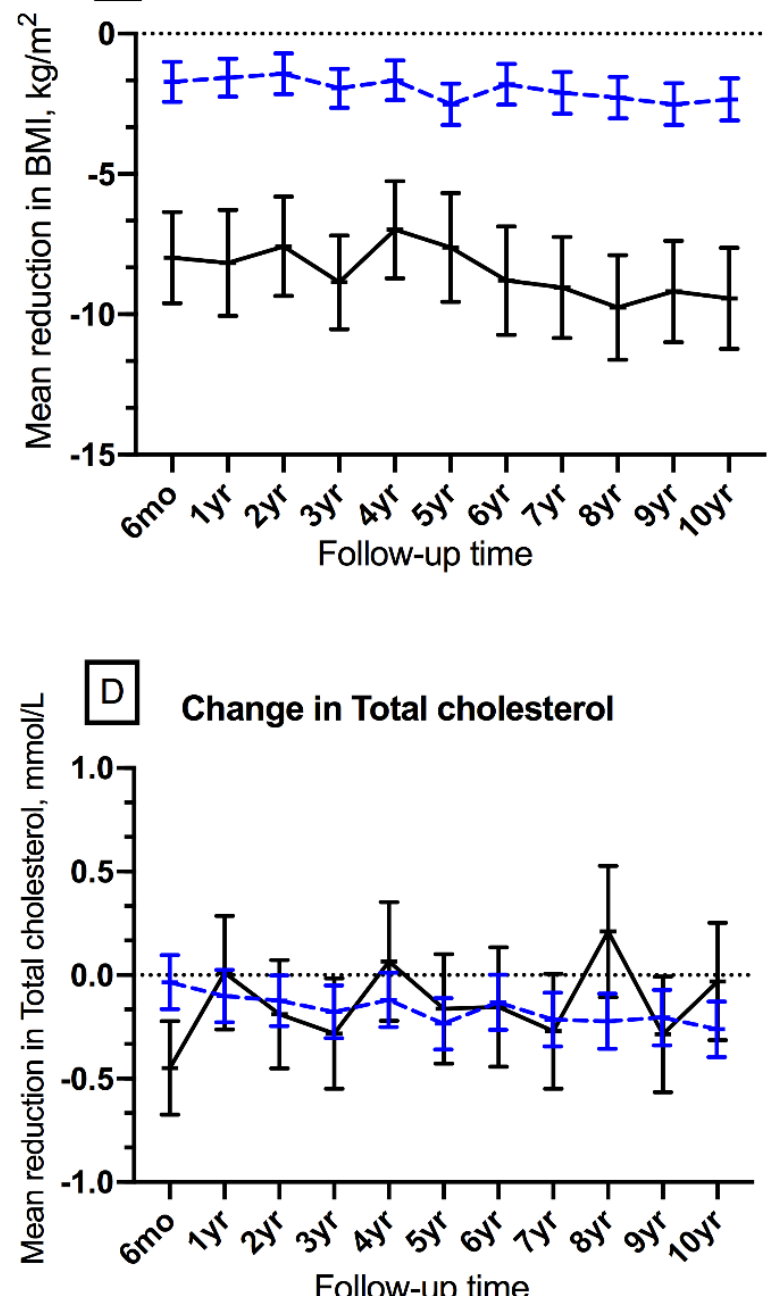

Follow-up time
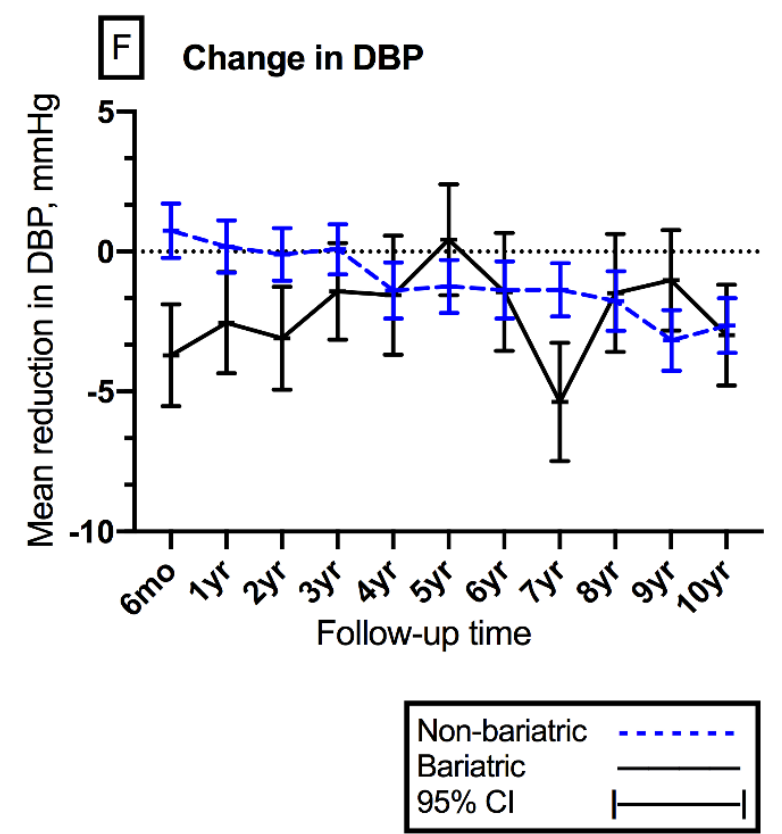
Figure S1. Mean difference in reduction in weight health outcome variables between the unmatched groups (full cohort) throughout 10 years of follow-up compared to baseline.

A Change in weight
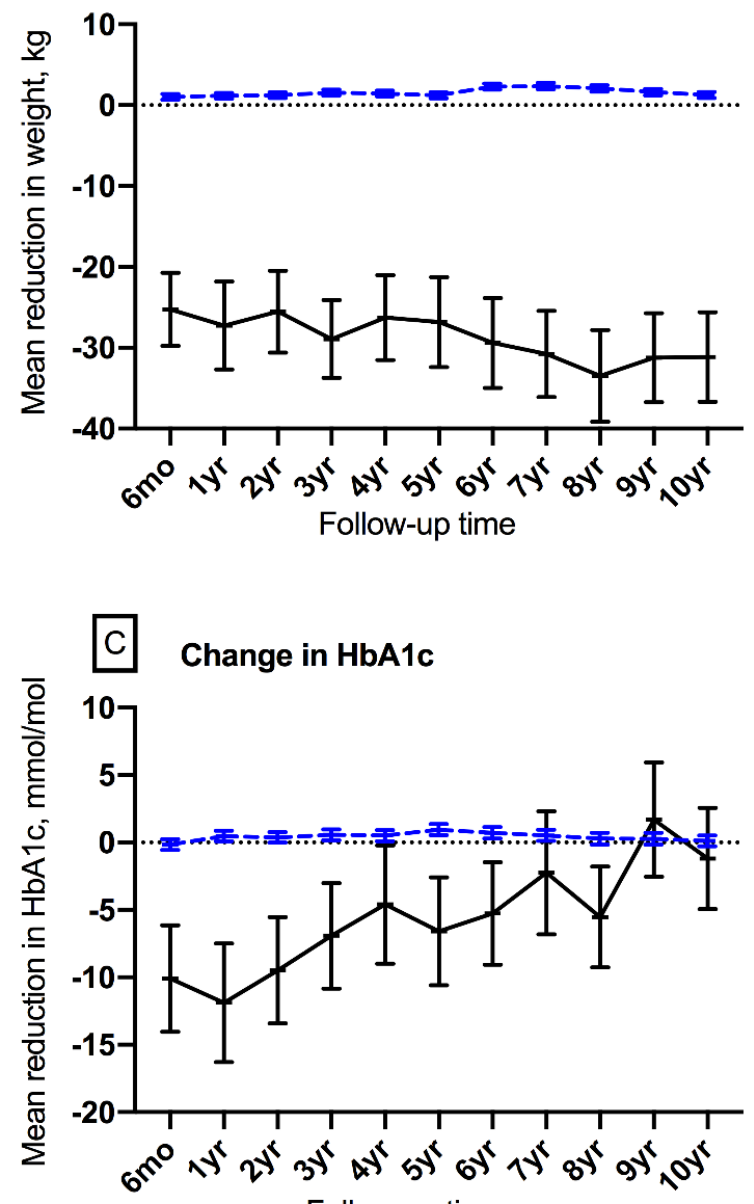

Follow-up time

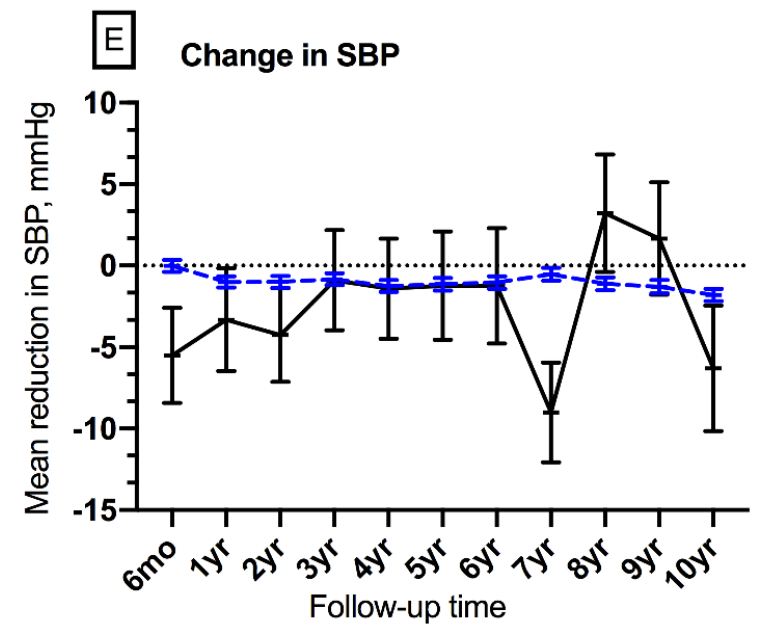

$B$ Change in BMI
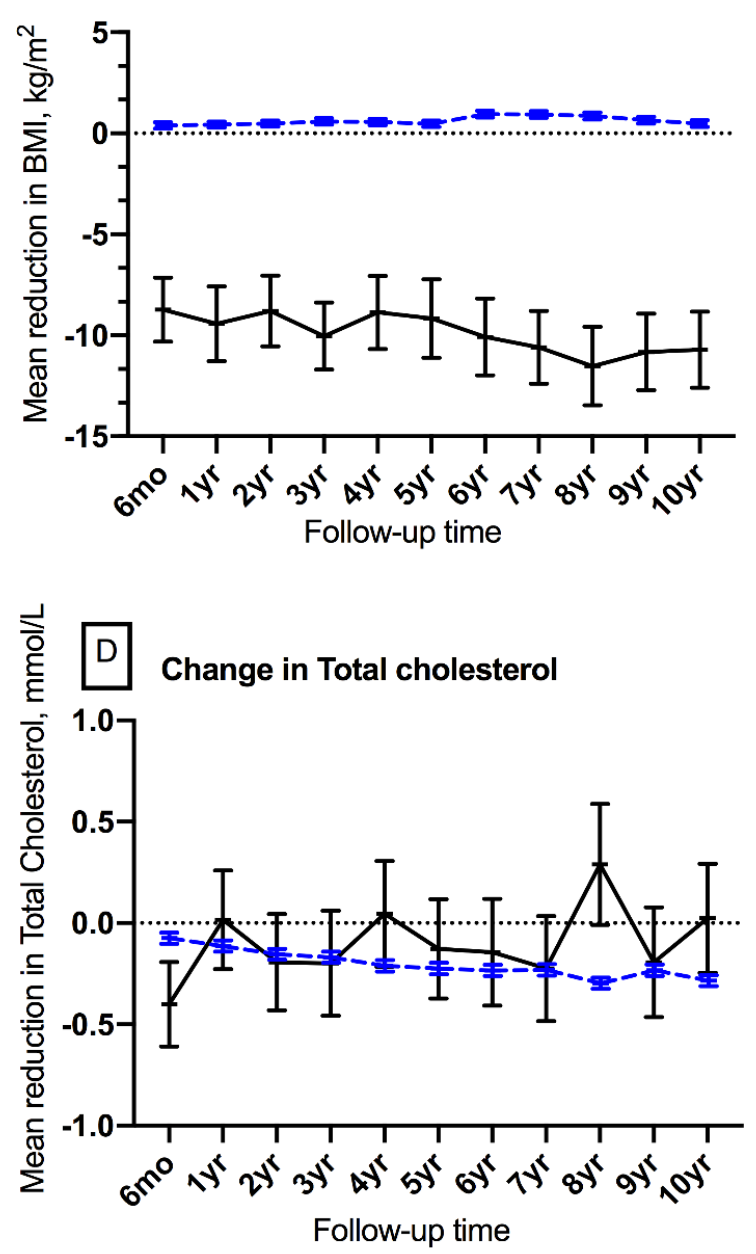

$F$ Change in DBP

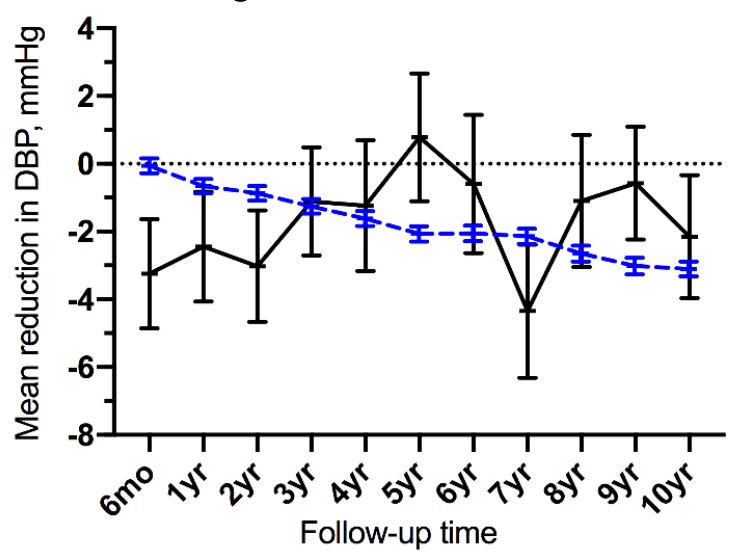

\begin{tabular}{|l} 
Non-bariatric \\
Bariatric \\
$95 \% \mathrm{Cl}$
\end{tabular} 
STROBE Statement — checklist of items that should be included in reports of observational studies

\begin{tabular}{|c|c|c|c|}
\hline & $\begin{array}{c}\text { Item } \\
\text { No }\end{array}$ & Recommendation & $\begin{array}{c}\text { Page } \\
\text { number }\end{array}$ \\
\hline \multirow[t]{2}{*}{ Title and abstract } & \multirow[t]{2}{*}{1} & $\begin{array}{l}\text { (a) Indicate the study's design with a commonly used term in the title or the } \\
\text { abstract }\end{array}$ & 1 \\
\hline & & $\begin{array}{l}\text { (b) Provide in the abstract an informative and balanced summary of what was } \\
\text { done and what was found }\end{array}$ & 2 \\
\hline \multicolumn{4}{|l|}{ Introduction } \\
\hline Background/rationale & 2 & $\begin{array}{l}\text { Explain the scientific background and rationale for the investigation being } \\
\text { reported }\end{array}$ & 4 \\
\hline Objectives & 3 & State specific objectives, including any prespecified hypotheses & 4 \\
\hline \multicolumn{4}{|l|}{ Methods } \\
\hline Study design & 4 & Present key elements of study design early in the paper & 5 \\
\hline Setting & 5 & $\begin{array}{l}\text { Describe the setting, locations, and relevant dates, including periods of } \\
\text { recruitment, exposure, follow-up, and data collection }\end{array}$ & 5,6 \\
\hline Participants & 6 & $\begin{array}{l}\text { (a) Cohort study-Give the eligibility criteria, and the sources and methods of } \\
\text { selection of participants. Describe methods of follow-up } \\
\text { Case-control study - Give the eligibility criteria, and the sources and methods } \\
\text { of case ascertainment and control selection. Give the rationale for the choice of } \\
\text { cases and controls } \\
\text { Cross-sectional study - Give the eligibility criteria, and the sources and } \\
\text { methods of selection of participants }\end{array}$ & 5,6 \\
\hline
\end{tabular}

(b) Cohort study_-For matched studies, give matching criteria and number of 6 exposed and unexposed

Case-control study-For matched studies, give matching criteria and the number of controls per case

\begin{tabular}{|c|c|c|c|}
\hline Variables & 7 & $\begin{array}{l}\text { Clearly define all outcomes, exposures, predictors, potential confounders, and } \\
\text { effect modifiers. Give diagnostic criteria, if applicable }\end{array}$ & 6,7 \\
\hline $\begin{array}{l}\text { Data sources/ } \\
\text { measurement }\end{array}$ & $8 *$ & $\begin{array}{l}\text { For each variable of interest, give sources of data and details of methods of } \\
\text { assessment (measurement). Describe comparability of assessment methods if } \\
\text { there is more than one group }\end{array}$ & 6,7 \\
\hline Bias & 9 & Describe any efforts to address potential sources of bias & 6,7 \\
\hline Study size & 10 & Explain how the study size was arrived at & 7 \\
\hline Quantitative variables & 11 & $\begin{array}{l}\text { Explain how quantitative variables were handled in the analyses. If applicable, } \\
\text { describe which groupings were chosen and why }\end{array}$ & $5-7$ \\
\hline \multirow[t]{7}{*}{ Statistical methods } & \multirow[t]{7}{*}{12} & $\begin{array}{l}\text { (a) Describe all statistical methods, including those used to control for } \\
\text { confounding }\end{array}$ & $6-7$ \\
\hline & & (b) Describe any methods used to examine subgroups and interactions & 7 \\
\hline & & (c) Explain how missing data were addressed & $6-7$ \\
\hline & & (d) Cohort study - If applicable, explain how loss to follow-up was addressed & \\
\hline & & Case-control study - If applicable, explain how matching of cases and controls & \\
\hline & & was addressed & \\
\hline & & $\begin{array}{l}\text { Cross-sectional study-If applicable, describe analytical methods taking } \\
\text { account of sampling strategy }\end{array}$ & \\
\hline
\end{tabular}

(e) Describe any sensitivity analyses 
Results

\begin{tabular}{|c|c|c|c|}
\hline \multirow[t]{3}{*}{ Participants } & \multirow[t]{3}{*}{$13 *$} & $\begin{array}{l}\text { (a) Report numbers of individuals at each stage of study-eg numbers potentially eligible, } \\
\text { examined for eligibility, confirmed eligible, included in the study, completing follow-up, } \\
\text { and analysed }\end{array}$ & \multirow[t]{3}{*}{8} \\
\hline & & (b) Give reasons for non-participation at each stage & \\
\hline & & (c) Consider use of a flow diagram & \\
\hline \multirow[t]{3}{*}{$\begin{array}{l}\text { Descriptive } \\
\text { data }\end{array}$} & \multirow[t]{3}{*}{$14 *$} & $\begin{array}{l}\text { (a) Give characteristics of study participants (eg demographic, clinical, social) and } \\
\text { information on exposures and potential confounders }\end{array}$ & $\begin{array}{c}8, \\
\text { Table } 1 \\
\end{array}$ \\
\hline & & (b) Indicate number of participants with missing data for each variable of interest & \\
\hline & & (c) Cohort study-Summarise follow-up time (eg, average and total amount) & 8 \\
\hline \multirow[t]{3}{*}{ Outcome data } & \multirow[t]{3}{*}{$15^{*}$} & Cohort study-Report numbers of outcome events or summary measures over time & $\begin{array}{c}8,9 \\
\text { Table } 2 \\
\end{array}$ \\
\hline & & $\begin{array}{l}\text { Case-control study-Report numbers in each exposure category, or summary measures of } \\
\text { exposure }\end{array}$ & \\
\hline & & Cross-sectional study_Report numbers of outcome events or summary measures & \\
\hline \multirow[t]{3}{*}{ Main results } & \multirow[t]{3}{*}{16} & $\begin{array}{l}\text { (a) Give unadjusted estimates and, if applicable, confounder-adjusted estimates and their } \\
\text { precision (eg, } 95 \% \text { confidence interval). Make clear which confounders were adjusted for } \\
\text { and why they were included }\end{array}$ & $\begin{array}{c}8-10, \\
\text { Table } 2\end{array}$ \\
\hline & & (b) Report category boundaries when continuous variables were categorized & \\
\hline & & $\begin{array}{l}\text { (c) If relevant, consider translating estimates of relative risk into absolute risk for a } \\
\text { meaningful time period }\end{array}$ & \\
\hline Other analyses & 17 & $\begin{array}{l}\text { Report other analyses done-eg analyses of subgroups and interactions, and sensitivity } \\
\text { analyses }\end{array}$ & 10 \\
\hline \multicolumn{4}{|l|}{ Discussion } \\
\hline Key results & 18 & Summarise key results with reference to study objectives & 10 \\
\hline Limitations & 19 & $\begin{array}{l}\text { Discuss limitations of the study, taking into account sources of potential bias or } \\
\text { imprecision. Discuss both direction and magnitude of any potential bias }\end{array}$ & 12 \\
\hline Interpretation & 20 & $\begin{array}{l}\text { Give a cautious overall interpretation of results considering objectives, limitations, } \\
\text { multiplicity of analyses, results from similar studies, and other relevant evidence }\end{array}$ & $11-12$ \\
\hline Generalisability & 21 & Discuss the generalisability (external validity) of the study results & 12 \\
\hline \multicolumn{4}{|c|}{ Other information } \\
\hline Funding & 22 & $\begin{array}{l}\text { Give the source of funding and the role of the funders for the present study and, if } \\
\text { applicable, for the original study on which the present article is based }\end{array}$ & NA \\
\hline
\end{tabular}

*Give information separately for cases and controls in case-control studies and, if applicable, for exposed and unexposed groups in cohort and cross-sectional studies.

Note: An Explanation and Elaboration article discusses each checklist item and gives methodological background and published examples of transparent reporting. The STROBE checklist is best used in conjunction with this article (freely available on the Web sites of PLoS Medicine at http://www.plosmedicine.org/, Annals of Internal Medicine at http://www.annals.org/, and Epidemiology at http://www.epidem.com/). Information on the STROBE Initiative is available at www.strobe-statement.org. 


\section{Please wait...}

If this message is not eventually replaced by the proper contents of the document, your PDF viewer may not be able to display this type of document.

You can upgrade to the latest version of Adobe Reader for Windows®, Mac, or Linux® by visiting http://www.adobe.com/go/reader_download.

For more assistance with Adobe Reader visit http://www.adobe.com/go/acrreader.

Windows is either a registered trademark or a trademark of Microsoft Corporation in the United States and/or other countries. Mac is a trademark of Apple Inc., registered in the United States and other countries. Linux is the registered trademark of Linus Torvalds in the U.S. and other countries. 


\section{Please wait...}

If this message is not eventually replaced by the proper contents of the document, your PDF viewer may not be able to display this type of document.

You can upgrade to the latest version of Adobe Reader for Windows®, Mac, or Linux® by visiting http://www.adobe.com/go/reader_download.

For more assistance with Adobe Reader visit http://www.adobe.com/go/acrreader.

Windows is either a registered trademark or a trademark of Microsoft Corporation in the United States and/or other countries. Mac is a trademark of Apple Inc., registered in the United States and other countries. Linux is the registered trademark of Linus Torvalds in the U.S. and other countries. 


\section{Please wait...}

If this message is not eventually replaced by the proper contents of the document, your PDF viewer may not be able to display this type of document.

You can upgrade to the latest version of Adobe Reader for Windows®, Mac, or Linux® by visiting http://www.adobe.com/go/reader_download.

For more assistance with Adobe Reader visit http://www.adobe.com/go/acrreader.

Windows is either a registered trademark or a trademark of Microsoft Corporation in the United States and/or other countries. Mac is a trademark of Apple Inc., registered in the United States and other countries. Linux is the registered trademark of Linus Torvalds in the U.S. and other countries. 


\section{Please wait...}

If this message is not eventually replaced by the proper contents of the document, your PDF viewer may not be able to display this type of document.

You can upgrade to the latest version of Adobe Reader for Windows®, Mac, or Linux® by visiting http://www.adobe.com/go/reader_download.

For more assistance with Adobe Reader visit http://www.adobe.com/go/acrreader.

Windows is either a registered trademark or a trademark of Microsoft Corporation in the United States and/or other countries. Mac is a trademark of Apple Inc., registered in the United States and other countries. Linux is the registered trademark of Linus Torvalds in the U.S. and other countries. 